\title{
The foraging gene affects alcohol sensitivity, metabolism and memory in Drosophila
}

\author{
Anne S. Oepen ${ }^{\mathrm{ab}}$, Jamie Catalano ${ }^{\mathrm{ac}}$, Reza Azanchi ${ }^{\mathrm{a}}$, and Karla R. Kaun ${ }^{\mathrm{a}, \mathbb{}}$ \\ ${ }^{a}$ Department of Neuroscience, Brown University, Providence, USA \\ ${ }^{\mathrm{b}}$ Masters Program in Developmental, Neuronal and Behavioral Biology, Georg-August-University, Goettingen, Germany \\ ${ }^{c}$ Molecular Pharmacology and Physiology Graduate Program, Brown University, Providence, USA
}

\begin{abstract}
The genetic basis of alcohol use disorder (AUD) is complex. Understanding how natural genetic variation contributes to alcohol phenotypes can help identify mechanisms underlying the genetic contribution of AUD. Recently, a single nucleotide polymorphism in the human foraging (for) gene ortholog, Protein Kinase cGMP-Dependent 1 (PRKG1), was found to be associated with stress-induced risk for alcohol abuse. However, the mechanistic role that PRKG1 plays in AUD is not well understood. We use natural variation in the Drosophila for gene to describe how variation of cGMP-dependent protein kinase (PKG) activity modifies ethanol-induced phenotypes. We found that variation in for affects ethanol-induced increases in locomotion and memory of the appetitive properties of ethanol intoxication. Further, these differences may stem from the ability to metabolize ethanol. Together, this data suggests that natural variation in PKG modulates cue reactivity for alcohol, and thus could influence alcohol cravings by differentially modulating metabolic and behavioral sensitivities to alcohol.
\end{abstract}

foraging | PRKG1 | cGMP-dependent protein kinase | alcohol | memory | metabolism | locomotion | AUD | Drosophila

Correspondence: karla_kaun@brown.edu

\section{Introduction}

Determining the mechanisms through which individual genes influence natural variation in behavior has been difficult due to the complexity of the genetic basis of heritable behavior. A notable exception to the genetic complexity underlying behavior is the foraging (for) gene in Drosophila melanogaster (1). Variants of for show increased (rovers or $f^{R}{ }^{R}$ ) or decreased (sitters or for $^{s}$ ) cGMP-dependent protein kinase (PKG) activity, which affects food search behavior (2). Rovers show increased pathlength while foraging, whereas sitters show decreased pathlength and stay longer at one food source $(1,3)$ for also causes phenotypical pleiotropy in flies, in part due to multiple promotors driving expression in different cell types (4), and at different developmental stages (57). The foraging gene affects foraging behavior $(1,8-13)$ ), fat and glucose stores $(4,14)$, food intake $(14,15)$, sucrose response $(16,17)$, sleep $(18)$, habituation $(17,19,20)$, nociception (21), oviposition (22), stress response (23-25), as well as learning and memory $(17,20,26-30)$

Moreover, for's role as a behavioral modifier in a wide range of behaviors is conserved across species including Apis mellifera (31), Xenopus laevis (32), Mus musculus (33), Caenorhabditis elegans $(34,35)$, and Homo sapiens $(36,37)$. Given for's conserved role, understanding the mechanistic actions through which for affects behavior may lead to insight regarding conserved functions of how natural genetic variation alters behavior.

More recently, Protein Kinase cGMP-Dependent 1 (PRKG1), the human ortholog of for $(36,38)$, was implicated in stress-induced risk for alcohol abuse $(39,40)$. A geneby-environment genome-wide interaction study (GEWIS) investigating mechanisms by which traumatic life events influence genetic variation in relation to alcohol misuse, revealed several risk alleles for alcohol use disorder (AUD) including PRKG1 (40). Similarly, a genome-wide association study (GWAS) implicated PRKG1 in other stressed induces phenotypes like post-traumatic stress disorder (41).

Other components of cGMP signaling have also been implicated in alcohol-associated phenotypes. Consumption of alcohol increases cGMP levels in the rat cortex, striatum and hippocampus (42). Increasing cGMP levels in the rat ventral tegmental area (VTA) or medial prefrontal cortex (mPFC) reduces the ability of alcohol deprivation to enhance drinking, which is reversed by inhibiting PKG (43). Finally, deletion of PKG type II in mice reduces alcohol's sedative effects and increases alcohol consumption (44). NO/cGC/cGMP/PKG signaling also causes neuroadaptive changes in synaptic activity, thereby affecting distinct forms of learning and memory, such as object recognition, motor adaptation and fear conditioning (45-48). This signaling pathway similarly inhibits dopamine release in brain regions that are involved in addiction (49-51), and contributes to cocaine self-administration (52) and morphine induced neuroadaptation (53). This compounding evidence suggests PRGK1 plays a critical role in alcohol consumption, and calls for a better understanding of for's mechanistic role in alcohol induced behaviors.

Drosophila has proven to be a valuable model organism for identifying genes and elucidating mechanisms associated with AUD (54-56). In addition to genomic, transcriptomic and proteomic approaches, simple forward and reverse genetic approaches can be performed to identify genes that affect alcohol-induced behaviors, and to elucidate the cellular and molecular mechanisms underlying candidate genes linked to AUD. Due to the huge variety of genetic tools available in Drosophila, many cell types, neural circuits and genes have been linked to an alcohol phenotype (57-73). Therefore, investigating for ${ }^{\text {s }}$ sole in relation to alcohol phenotypes in the fly might help to unravel the function of PRKG1 in alcohol addiction in humans. 


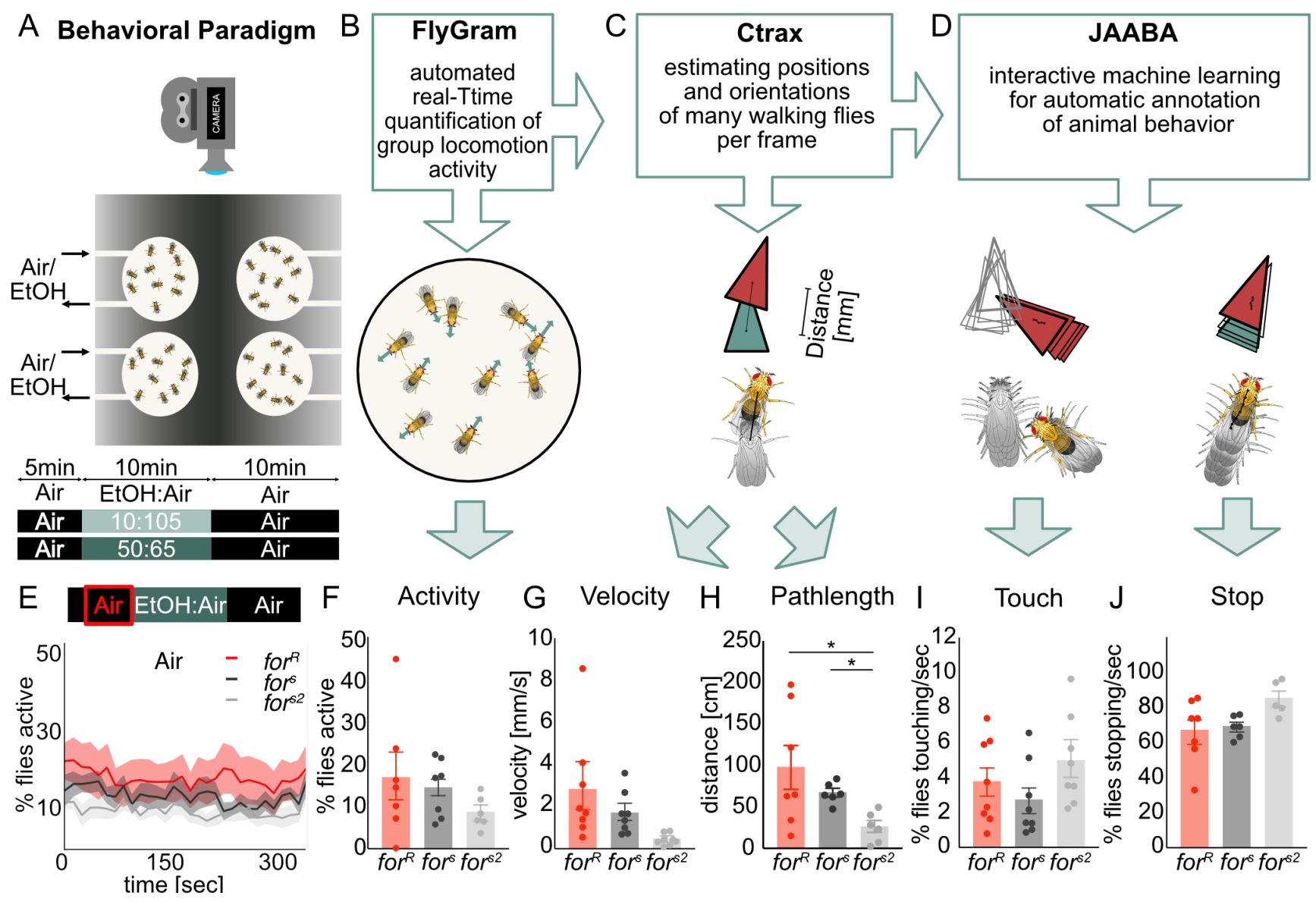

Fig. 1. for does not affect spontaneous open field behavior. A)The flyGrAM arena consists of 4 circular arenas each filled with 10 flies of different strains. Flies were tracked while being given humidified air for $5 \mathrm{~min}$, ethanol for $10 \mathrm{~min}$, then humidified air for $5 \mathrm{~min}$. (B) Group activity within each arena was analyzed with the FlyGrAM software while recording the flies during the behavioral paradigm. (C) Ctrax was used to estimate the position and orientation of the 10 flies in each arena per frame. (D) The interactive machine learning for automatic annotation of animal behavior (JAABA) was fed per-frame feature information from ctrax to reveal information about social interaction of the flies. (E,F) Lines depict mean+/- standard error. (F-J) Graphs show mean+/- standard error. The spontaneous activity levels of flies given humidified air remain at $15 \%$ and show no significant difference between strains. (G) Velocity of flies given humidified air for $5 \mathrm{~min}$ is between $1-3 \mathrm{~mm} / \mathrm{s}$ with no significant difference between strains. (H) Flies cover distances between $30-100 \mathrm{~cm}$ in five minutes, with no significant differences between strains. (I) Less than $5 \%$ of the flies touch per second when given humidified air, with no significant differences between strains. (J) More than $60 \%$ of the flies show stopping behavior per second when given humidified air, with no significant differences between strains.

\section{Material and Methods}

Fly Stocks and Rearing Conditions. The following fly strains were used: for $^{s}$ (sitter), for $^{R}$ (rover) and for $^{s 2} \cdot$ for $^{s}$ and $f \circ r^{R}$ flies carry the natural rover/sitter polymorphisms in for. $f r^{2}$ flies have a rover genetic background but carry a gamma radiation-induced mutation in for that results in lower PKG activity levels and sitter behavior in many of the forrelated phenotypes $(2,10,11)$. However, the for $^{s 2}$ mutant does not always affect for-dependent phenotypes, and to our knowledge, specific alterations in DNA sequence as a result of the s2 mutation are unknown $(74,75)$. Flies were raised on standard cornmeal agar food media with tegosept anti-fungal agent. Flies were kept at $24^{\circ} \mathrm{C}$ and $65 \%$ humidity with a 14/10-hour light/dark cycle. Male flies for all strains were collected 1-2 days after hatching and used for behavioral experiments at day 3-5 after eclosion.

Group Activity. In order to analyze the ethanol-induced changes in activity, we used a video based behavioral apparatus and software that enables an automatic quantification of group locomotion activity in Drosophila (70) (Fig 1A). The fly Group Activity Monitor (FlyGrAM) consists of four circular arenas that are all individually connected to an air and vacuum source to allow for a constant airflow (Fig 1A,B). Each arena is $37 \mathrm{~mm}$ diameter, $2.5 \mathrm{~mm}$ tall, and covered with a clear acrylic sheet allowing the flies to walk freely in the arena, but preventing them from flying. Ten male flies $\left(f^{s} r^{s}\right.$, $f o r^{R}$ or $f_{0}{ }^{22}$ ) were placed in each circular arena and placed at $24^{\circ} \mathrm{C}$ for 10 minutes to provide time for flies to adapt to the arena environment. Next, the arena with the flies was placed in the tracking apparatus, and flies were provided a constant humidified airflow of 115 units ( $1856 \mathrm{ml} / \mathrm{min}$ ) for $15 \mathrm{~min}$ utes, which allowed their locomotion to decrease to a stable baseline (Fig 1A).

Ten flies were gently placed via mouth pipette into each arena, and initially provided humidified airflow for five minutes to gain a measurement of baseline activity. Subsequently, vaporized ethanol was introduced to the flies in the arena by changing the gas flow-through to a mix of ethanol:air ratio (high concentration: 50:65, low concentra- 

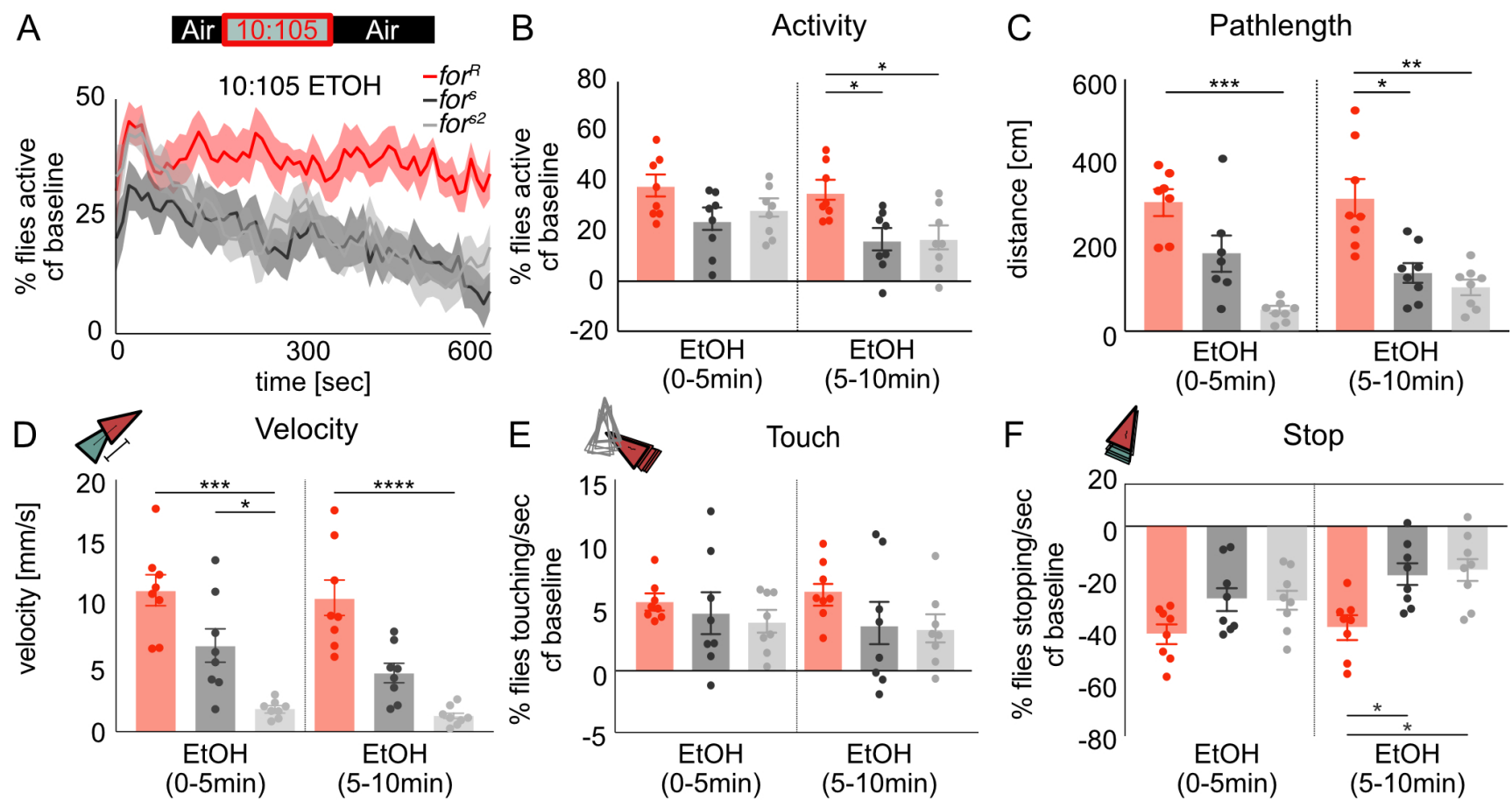

Fig. 2. . for affects activity in response to ethanol odor (A,B) During the period of low-dose ethanol exposure, the activity for $f \circ r^{s}$ and $f \circ r^{s 2}$ decreased, whereas the activity level of for ${ }^{R}$ stayed the same. Lines depict mean+/- standard error. (B-F) Graphs show mean+/- standard error. (C) for ${ }^{R}$ traveled significantly longer distances during low dose ethanol exposure compared to $f o r^{s}$ and $f \circ r^{2}$ flies. (D) for ${ }^{R}$ show a significantly higher velocity compared to for ${ }^{s}$ and for ${ }^{2}$ flies. $(E, F)$ Touching behavior increases for all strains compared to open field behavior whereas stopping behavior significant decreased to less than $60 \%$ of the flies stopping per second. for ${ }^{R}$ stopped significantly less than $f \circ r^{s}$ and for ${ }^{s 2}$ flies. n.s. $=p>0.05,{ }^{*}=p<0.05,{ }^{* *}=p<0.01,{ }^{* * *}=p>0.001,{ }^{* * * *}=p<0.0001$ )

tion: 10:105) for 10 minutes. Finally, the airflow was shifted back to $100 \%$ air for 10 minutes (Fig 1A). The group activity of the flies are automatically recorded for the entire duration (70). Each experiment was replicated 8 times $(n=8$ comprises 8 groups of 10 flies per group, thus 80 flies). In order to ensure no strain-specific effects were due to a single arena and no spatial bias of placement within the apparatus, the strains tested were counterbalanced across arenas. Experiments were run at a steady temperature around $24^{\circ} \mathrm{C} \pm 1.5^{\circ} \mathrm{C}$ in a dark chamber to reduce the influence of visual cues on group activity.

High Content Tracking. FlyGrAM videos were analyzed using Ctrax (Branson et al., 2009) to extract information about individual flies' position, orientation and trajectories (Fig 1B). The output of Ctrax tracking is an ellipse fit to each fly within an arena throughout the experiment. It is defined by the centroid, the fly's orientation as well as the length of two body axis, the minor and major body axis, needed for the calculation of the perframe features. For example, velocity is defined as the speed of the center of rotation, being the point on the fly that translates the least from one frame to the next. The velocity is calculated by the magnitude of the vector between the fly's center of rotation in frames $t 1$ to $t$, normalized by the frame rate (76). This allowed us to gain information about the velocity of the flies per frame. Total distance travelled (pathlength) before, during and after ethanol exposures was calculated as the integral of speed, i.e. sum- ming the perframe (30fps) velocities $(\mathrm{mm} / \mathrm{s})$ measured during 5 minutes. JAABA Classifiers (77) were trained on the Ctrax perframe features to gain information about specific social and locomotion behaviors: Touch and Stop (Fig 1C). The JAABA learning algorithm is fed with specific pre-defined behavioral classifiers in order to scan across all frames for the classified behavior. In this study we made use of the existing classifiers for stopping and touching behavior introduced by Branson and colleagues (77). To further analyze the effect of ethanol on these behavioral features, the data was split into 4 phases each lasting 5 minutes, baseline $(0-5 \mathrm{~min})$, early ethanol(5-10min), late ethanol(10-15min) and recovery(1520min). The Stop and Touch data was normalized to the baseline behavior to detect changes in these features caused by alcohol exposure.

Memory for Ethanol Reward. To test whether for affected the ability to associate a cue with ethanol, we exposed $f o r^{R}, f o r^{s}$ and for $^{s 2}$ flies to two consecutive odor cues (1:36 isoamyl alcohol or ethyl acetate in mineral oil) with the second odor paired with an intoxicating dose of $60 \%$ ethanol vapor $(90: 60$ ethanol:air) $(78,79)$. Flies were exposed to 10 $\mathrm{min}$ of the first odor followed by $10 \mathrm{~min}$ of the second odor, which is paired with $60 \%$ ethanol vapor. Flies were trained three times with 50 min breaks between each session. Flies were placed in perforated $14 \mathrm{~mL}$ canonical tubes with mesh lids, and placed in $30 \mathrm{~cm} \times 15 \mathrm{~cm} \times 15 \mathrm{~cm}$ training boxes with passive vacuum while being exposed to odors and ethanol 

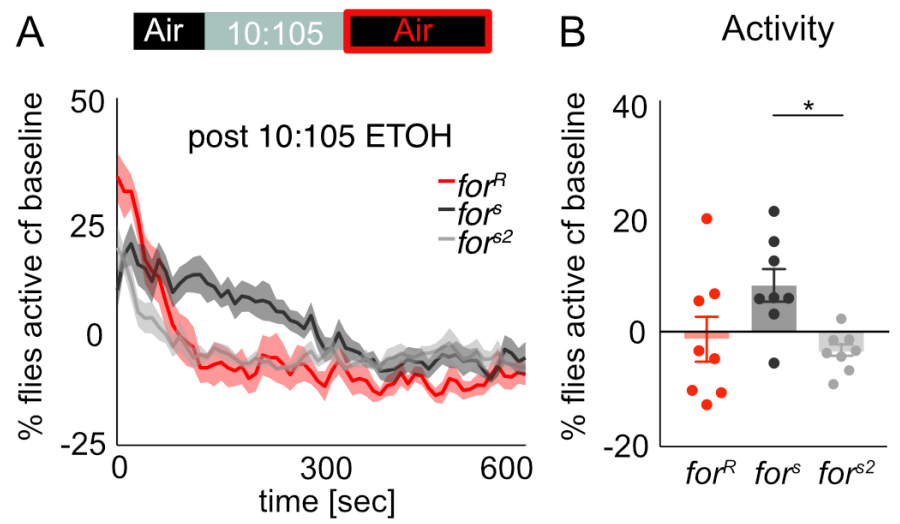

C Pathlength
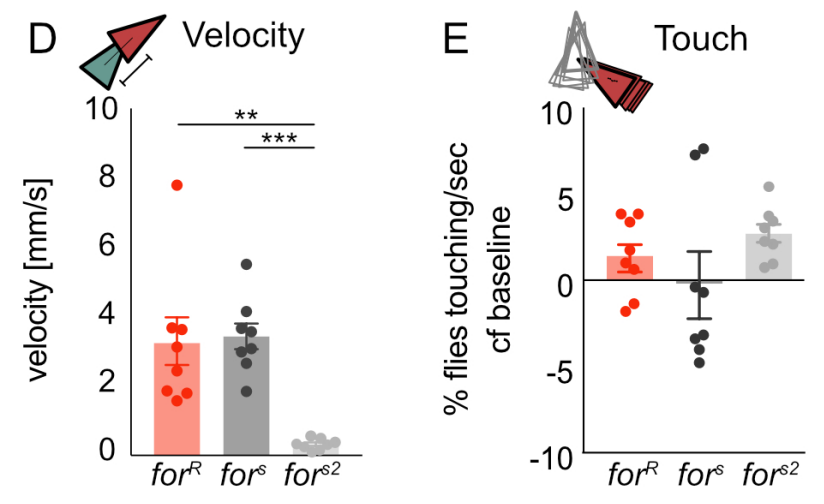

vapor. To avoid a naïve odor bias, reciprocal odor controls were run simultaneously. $30 \mathrm{~min}$ or 24 hours after training, flies were given a choice between unpaired and paired odors in a Y-maze (79) (Fig 6A). A preference index was calculated by subtracting the number of flies entering the unpaired odor vial from the paired odor vial, and dividing this number by the total number of flies tested (78). A conditioned preference index was calculated by averaging the preference index of the two reciprocal training sessions. 60 flies were used for each $\mathrm{N}=1,30$ flies for each reciprocal conditioning. $\mathrm{N}=20-26$ for each strain per condition.

Alcohol Metabolism. To investigate how the different for strains absorb and metabolize alcohol, we exposed flies to $60 \%$ vaporized ethanol (90:60 ethanol:air) for $10 \mathrm{~min}$ and measured internal ethanol concentration immediately after or 30 min after ethanol exposure. The internal ethanol concentrations were determined from whole fly homogenates of 50 flies per sample (78). To measure the ethanol concentration, flies were first flash frozen in liquid nitrogen, and then homogenized in $500 \mu \mathrm{l}$ Tris-HCL (50mM, pH 7.5, Sigma), followed by centrifugation at $4^{\circ} \mathrm{C}$ at 14000 r.p.m. for $20 \mathrm{~min}$. Next, the ethanol concentration of the supernatant was measured using an alcohol dehydrogenase-based spectrophotometric assay (Ethanol Assay Kit 229-29, Diagnostic Chemicals) (Fig 7A). To set this data in relation and thereby calculate the fly internal ethanol level, the flies volume was set to $2 \mu \mathrm{l}(80)$.

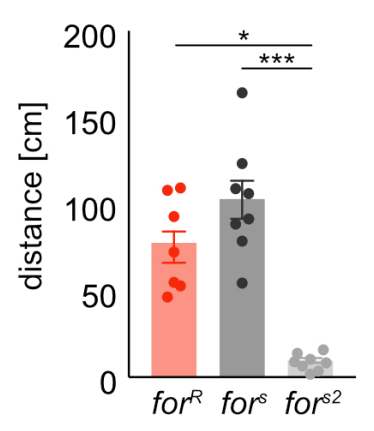

Fig. 3. for does not affect recovery from ethanol odor exposure $(A, B)$ During presentation of humidified air following exposure to lowdose ethanol, the group activity returns to baseline activity with $300 \mathrm{sec}$, with no significant differences between strains. Lines depict mean+/standard error. (B-F) Graphs show mean+/- standard error.(C) The total distance travelled (pathlength) after low-dose ethanol exposure returns to baseline behavior in $f o r^{R}$ and $f o r^{s 2}$ flies, whereas for flies still show an increase pathlength compared to baseline. (D) The velocity after low-dose ethanol exposure returns to baseline behavior in for $^{R}$ and $f \circ r^{s 2}$ flies, whereas $f \circ r^{s}$ flies still show an increase velocity compared to baseline., (E,F) Touch and Stop behavior recover within minutes of humidified air post ethanol odor. for $^{s}$ flies demonstrate less stopping than both for $^{R}$ and for ${ }^{s}$ flies. Since there were no consistent differences between rovers and the two sitter strains in any of the metrics reported, we do not attribute these behavioral differences to variation in for. n.s. $=p>0.05$, ${ }^{*}=p<0.05, \quad{ }^{* *}=p<0.01, \quad{ }^{* * *}=p>0.001$, ${ }^{* * * *}=p<0.0001$
Statistical Analysis. For statistical analysis the locomotion activity data were split in four phases, baseline (0300s), early ethanol (300-600s), late ethanol (600-900s), and recovery(900-1200s). All early ethanol, late ethanol and recovery data was normalized to baseline. Data for activity, velocity, touch and stop for each phase was averaged and analysed. Due to low sample size $(n=8)$ in behavior tracking experiments, we used more conservative non-parametric tests for the statistical analysis. This increased rigor, ensured consistency in analyses, and allowed for easier comparisons between experiments. For comparisons between the three nonpaired strains, a Kruskal Wallis test followed by Dunnett's multiple comparisons was performed. In order to analyze changes in behavior of each strain over time (paired data), a Friedmann test followed by paired Wilcoxon multiple comparisons was performed (n.s. $=\mathrm{p}>0.05,{ }^{*}=\mathrm{p}<0.05,{ }^{*} * \mathrm{p}<0.01$, $* * *=\mathrm{p}>0.001, * * * *=\mathrm{p}<0.0001)$. The statistical analysis was performed in PRISM 7 (GraphPad).

\section{Results}

foraging does not affect open field behaviour in the absence of a stimulus. We first tested whether rovers $\left(\right.$ for $\left.{ }^{R}\right)$, sitters $\left(\right.$ for $\left.^{s}\right)$ and sitter mutants with a rover background $\left(f o r^{s 2}\right)$ differ in spontaneous behavior in an open field arena without an ethanol stimulus, which we termed 'baseline' (Fig 1A,B). We found all for strains showed the same levels of group activity $\left(\mathrm{H}_{(3,24)}=0.29, \mathrm{P}=0.8\right)($ Fig $1 \mathrm{E}, \mathrm{F})$, velocity $\left(\mathrm{H}_{(3,24)}=4.63, \mathrm{P}=0.1\right.$ (Fig $\left.1 \mathrm{G}\right)$, touching $\left(\mathrm{H}_{(3,24)}=0.08\right.$, $\mathrm{P}=0.9)($ Fig $1 \mathrm{I})$ and stopping $\left(\mathrm{H}_{(3,24)}=0.4, \mathrm{P}=0.8\right)($ Fig $1 \mathrm{~J})$. 


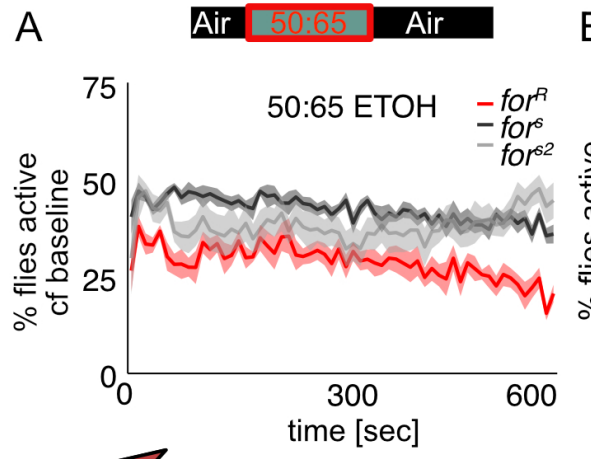

B

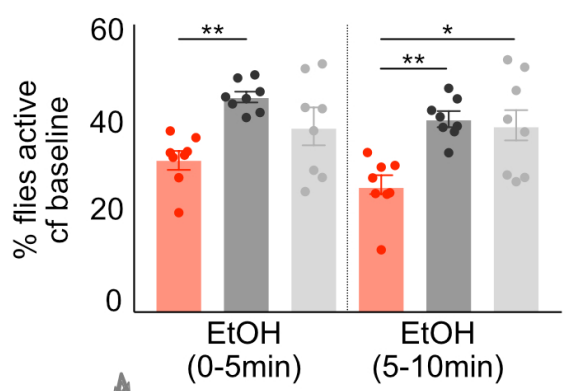

C

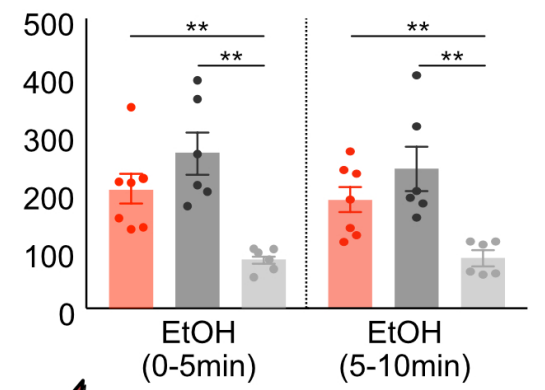

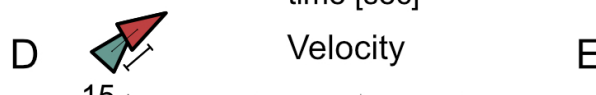
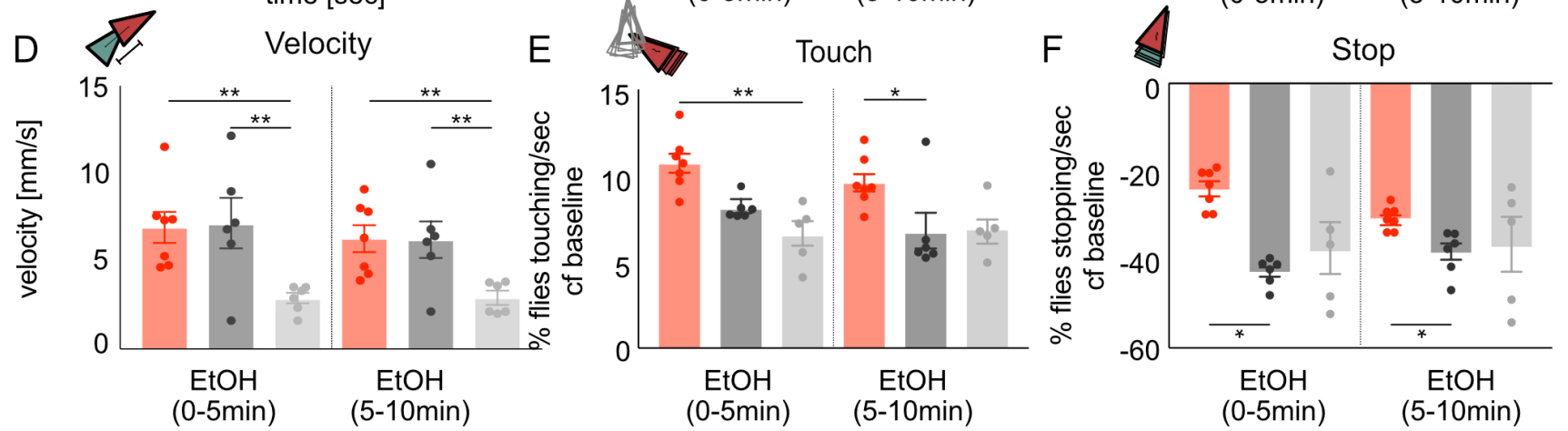

Fig. 4. for affects behavioral sensitivity to the pharmacological properties of ethanol (A)The percent activity in response to a high dose of ethanol increases to $35 \%$ for rovers and $45 \%$ for sitters. Lines depict mean+/- standard error. (B-F)Graphs show mean+/- standard error. (B) During high dose ethanol exposure the group activity of $f \circ r^{R}$ is significantly lower than $f \circ r^{s}$ and $f \circ r^{s}$ flies. (C) $f \circ r^{s 2}$ flies move a significantly smaller distance than for $r^{R}$ and $f \circ r^{s}$ flies. (D) for $r^{2}$ flies are significantly slower than for $^{R}$ and for $r^{S}$ flies. (E,F) All strains showed increased touching and decreased stopping during high-dose ethanol exposure. for ${ }^{R}$ showed significantly more touching than for $r^{s}$ and $f \circ r^{s}(E)$ and significantly more stopping than $f \circ r^{s}$ and $f \circ r^{s}$ flies in the first five minutes of ethanol exposure $(F) . n . s .=p>0.05,{ }^{*}=p<0.05,{ }^{* *}=p<0.01,{ }^{* * *}=p>0.001$, ${ }^{* * * *}=\mathrm{p}<0.0001$

The pathlength of $f r^{s 2}$ flies was significantly shorter compared to for $^{s}$ and for $^{R}$ (Fig $\left.1 \mathrm{H}\right)\left(\mathrm{H}_{(3,24)}=7.88, \mathrm{P}=0.01\right)$. In general, flies showed a high percentage of stopping behavior (70\%, Fig $1 \mathrm{~J}$ ), and only around $4 \%$ of the flies in each arena interacted with each other (Fig 1I).

\section{foraging affects locomotion in response to an ethanol}

odor. We then looked at whether for elicited foraging behavior in response to a non-intoxicating ethanol dose similar to that found in fermenting fruit (Levey, 2004). When the flies were exposed to a non-intoxicating $10 \mathrm{~min}$ exposure of 10:105 ethanol:air ratio, the percent of flies' activity increased to up to $40 \%$ in for $^{R}$ flies $(\mathrm{p}=0.008)$ and only $25 \%$ in for $^{s}(\mathrm{p}=0.008)$ and for $^{s 2}(\mathrm{p}=0.008)$ flies compared to baseline activity levels (Fig $2 \mathrm{~A}$ ). for $^{R}$ flies demonstrated an increased group activity throughout the 10-minute ethanol exposure whereas $f_{o r}{ }^{s}$ and for $^{s 2}$ flies steadily decreased activity over time, resulting in a significantly lower activity at the end of ethanol exposure compared to $f o r^{R}$ flies $\left(\mathrm{H}_{(3,24)}=7.96, \mathrm{P}=0.02\right.$, for $^{R}$ vs for $^{s}(\mathrm{p}=0.01)$, for $^{R}$ vs $\left.\operatorname{for}^{s 2}(\mathrm{p}=0.02)\right)($ Fig $2 \mathrm{~B})$. Rovers travelled significantly longer distances during low dose ethanol exposure compared to sitters $\left(0-5\right.$ min: $\mathrm{H}_{(3,24)}=13.92, \mathrm{P}<0.0001$, for $^{R}$ vs for $^{s 2}(\mathrm{p}=0.0006), 5-10 \mathrm{~min}: \mathrm{H}_{(3,24)}=13.72, \mathrm{P}=0.0011$, for $^{R}$ vs for $^{s}(\mathrm{p}=0.02)$, for $^{R}$ vs for $\left.^{s 2}(\mathrm{p}=0.001)\right)$ (Fig 2C). for ${ }^{R}$ flies also show a significantly higher velocity over the time of low dose ethanol exposure compared to $f^{s} r^{s}$ and for $^{s 2}$ flies $\left(\mathrm{H}_{(3,24)}=18, \mathrm{P}=0.0001\right.$, for $^{R}$ vs for $^{s} \quad(\mathrm{p}=0.002)$, for $^{R}$ vs for $\left.^{22}(\mathrm{p}<0.0001)\right)$ (Fig 2D). Our values are comparable to a previous study that reported in the presence of food rovers walked $36.17 \mathrm{~cm} / 30 \mathrm{sec}(361.7 \mathrm{~cm} / 5 \mathrm{~min})$, and sitters walked $17.38 \mathrm{~cm} / 30 \mathrm{sec}(173.8 \mathrm{~cm} / 5 \mathrm{~min})$, suggesting that the low dose ethanol here represents a food-like odor to the fly $(10,81)$. Ethanol odor increased touching $\left(\right.$ for $^{R}$ $(\mathrm{p}=0.008)$, for $^{s}(\mathrm{p}=0.02)$, for $\left.^{s 2}(\mathrm{p}=0.04)\right)$ and decreased stopping $\left(\right.$ for $^{R}(\mathrm{p}=0.008)$, for $^{s}(\mathrm{p}=0.008)$, for $\left.^{s 2}(\mathrm{p}=0.008)\right)$ in all strains (Fig $2 \mathrm{E}, \mathrm{F})$. for did not significantly affect touching $\left(\mathrm{H}_{(3,24)}=1.665, \mathrm{P}=0.43\right)$ (Fig $\left.2 \mathrm{E}\right)$. However, rovers stopped significantly more than sitters after five minutes of ethanol exposure $\left(\mathrm{H}_{(3,24)}=9.38, \mathrm{P}=0.009\right.$, for $^{R}$ vs for $^{s}(\mathrm{p}=0.03)$, for $^{R}$ vs for $\left.^{s}(\mathrm{p}=0.02)\right)$ (Fig 2F).

\section{foraging does not affect behaviour post-ethanol odor} stimulus. We hypothesized that once the ethanol odor stimulus was removed, all strains would recover to baseline behavior, resulting in no differences in behavioral measures between the three for strains. As predicted, there were no significant differences in group activity between rovers and sitters (Fig 3A) $\left(\right.$ for $^{R}$ vs for $^{s}(\mathrm{p}=0.06)$, for $^{R}$ vs $\left.f o r^{s 2}(\mathrm{p}>0.99)\right)$. Although there was a reduction in pathlength $\left(\mathrm{H}_{(3,24)}=15.7\right.$, $\mathrm{P}=0.0004)$, and velocity $\left(\mathrm{H}_{(3,24)}=15.61, \mathrm{P}=0.0004\right)$ in for $^{\text {s2 }}$ flies, and in stopping in for $^{s}$ flies $\left(\mathrm{H}_{(3,24)}=9.97, \mathrm{P}=0.007\right)$, there were no consistent significant differences between for $^{R}$ and the two sitter strains in any of the metrics reported, so we do not attribute these differences to variation in for (Fig 3 AF). There were no significant differences in touching between 

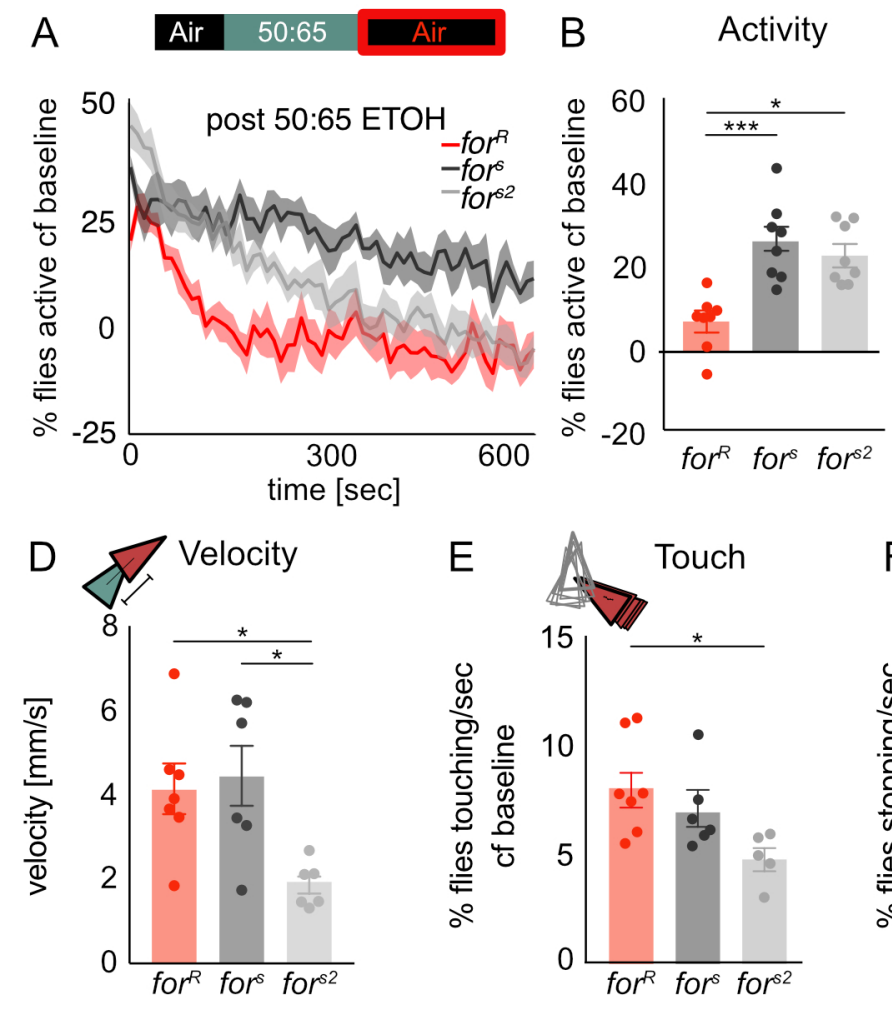

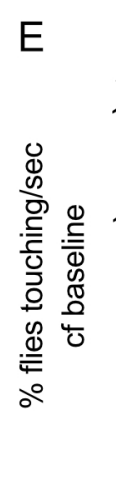

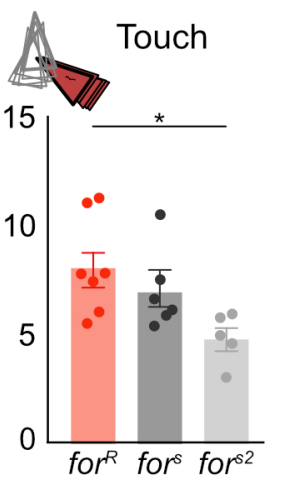

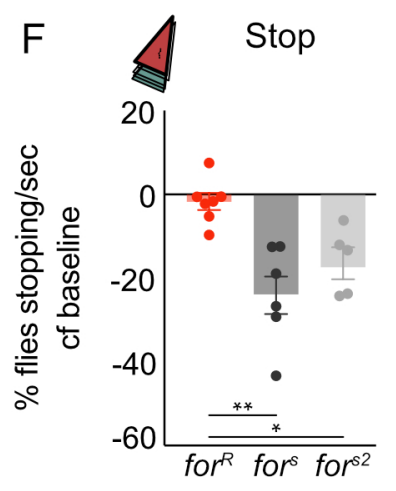

Fig. 5. for affects recovery from the pharmacological properties of ethanol (A)During exposure to humidified air following an intoxicating dose of ethanol, fly activity decreases more rapidly in $f^{R}{ }^{R}$ than $f o r^{s}$ or $f o r^{s 2}$ flies. Lines depict mean+/- standard error. (B-F) Graphs show mean+/- standard error. (BF) Graphs show mean+/- standard deviation (B) Significantly fewer for ${ }^{R}$ flies were active compared to for $^{S}$ and $f o r^{2}$ flies. (C) There is significantly reduced (C) pathlength and (D) velocity in $\mathrm{for}^{2}$ flies compared to for $^{R}$ and for flies (E) Touching behavior remained higher than baseline levels for all strains, and was statistically reduced in for $^{\text {s }}$ compared to $f \circ r^{R}$ flies (F) for ${ }^{R}$ stopping behavior returned to baseline levels whereas $f \circ r^{s}$ and $f o r^{s 2}$ flies continued to show significantly less stopping compared to baseline. n.s. $=p>0.05$, ${ }^{*}=p<0.05, \quad{ }^{* *}=p<0.01, \quad{ }^{* * *}=p>0.001$, ${ }^{* * * *}=p<0.0001$ the three strains $\left(\mathrm{H}_{(3,24)}=3.55, \mathrm{P}=0.17\right)(\mathrm{Fig} 3 \mathrm{E})$.

foraging affects ethanol-induced increases in locomotion and touching. We next investigated how variants of for affected these behavioral metrics in response to a dose of ethanol that typically induces sustained increases in locomotor activity (Scaplen et al., 2019), by exposing the flies to a 50:65 ethanol:air mixture (43\% ethanol vapor) for 10 minutes. Sitter strains increased group activity by $40 \%\left(\right.$ for $^{s}(\mathrm{p}=0.008)$, for $^{s 2}(\mathrm{p}=0.008)$ whereas rovers only showed $30 \%$ activity increase $\left(\right.$ for $^{R}(\mathrm{p}=0.02)$ compared to baseline (Fig 4A). During ethanol exposure, for $^{R}$ flies showed a significantly lower activity than sitters $\left(\mathrm{H}_{(3,19)}=10.9, \mathrm{P}=0.004\right.$, for $^{R}$ vs for ${ }^{s}(\mathrm{p}=0.006)$, for $^{R}$ vs for $^{s 2}$ $(\mathrm{p}=0.04))($ Fig $4 \mathrm{~B})$. However, for $^{R}$ did not show significantly less distance moved $(\mathrm{p}>0.9)$ or velocity $(\mathrm{p}>0.9)$ compared to $f o r^{s}$. for ${ }^{s 2}$ flies showed significantly reduced pathlength $\left(\mathrm{H}_{(3,19)}=12.33, \mathrm{P}=0.0002\right)$ and velocity compared to for $^{s}$ and for $^{R}$ flies $\left(\mathrm{H}_{(3,19)}=9.47, \mathrm{P}=0.004\right)$, but since for $^{R}$ flies did not differ from both sitter strains, we do not attribute these differences to variation in for. This dose of ethanol increased touching $\left(\right.$ for $^{R}(\mathrm{p}=0.02)$, for $^{s}(\mathrm{p}=0.03)$, for $\left.^{s 2}(\mathrm{p}=0.04)\right)(\mathrm{Fig}$ $4 \mathrm{E})$ and decreased stopping $\left(\right.$ for $^{R}(\mathrm{p}=0.03)$, for $^{s}(\mathrm{p}=0.03)$, $\left.f o r^{s 2}(\mathrm{p}=0.04)\right)$ in all strains (Fig 4F). During early ethanol exposure, for ${ }^{R}$ flies showed significantly more touching $\left(\mathrm{H}_{(3,19)}=12.19, \mathrm{p}=0.0002\right)$ than for $^{s 2}(\mathrm{p}=0.002)$, whereas this effect trended towards significance with for $^{s}$ ( $\mathrm{p}=0.06$ ). In contrast, for $^{R}$ flies showed significantly more touching $\left.\left(\mathrm{H}_{(3,19)}\right)=6.53, \mathrm{p}=0.03\right)$ than for $^{s}(\mathrm{p}=0.04)$ but not for $^{s 2}$ $(\mathrm{p}=0.2)$ during late ethanol exposure (Fig 4E). for $^{R}$ flies showed significantly more stopping $\left(\mathrm{H}_{(3,19)}=9.17, \mathrm{P}=0.005\right)$ than for $^{s}(\mathrm{p}=0.01, \mathrm{p}=0.04)$ but not for $^{s 2}(\mathrm{p}=0.1, \mathrm{p}=0.9)$ flies during early and late high-dose ethanol exposure (Fig 4E). .

\section{foraging affects recovery from the pharmacological} properties of ethanol. We hypothesized that since for affected the percent of flies active during ethanol intoxication, it may also affect recovery from the pharmacological properties of ethanol. Indeed, significantly fewer rover flies were active compared to sitters after the offset of ethanol $\left(\mathrm{H}_{(3,19)}=14.22, \mathrm{P}=0.0008\right.$, for $^{R}$ vs for $^{s}(\mathrm{p}=0.0009)$, for $^{R}$ vs $\left.f r^{s^{2}}(\mathrm{p}=0.02)\right)\left(\right.$ Fig 5A,B). However, for $^{R}$ flies moved significantly more distance than for $^{s 2}$ flies $(\mathrm{p}=0.04)$ but not for $^{s}$ flies ( $>>0.9$ ) (Fig 5C). for ${ }^{R}$ pathlengths returned to baseline within $5 \mathrm{~min}$ of recovery $(\mathrm{p}=0.4)$, which was not the case for $f^{s} r^{s}(\mathrm{p}=0.03)$ or for $^{s 2}(\mathrm{p}=0.03)$. Similarly, for ${ }^{R}$ flies moved significantly faster than for $^{s 2}$ flies $(\mathrm{p}=0.03)$ but not for $^{s}$ flies $(\mathrm{p}>0.9)$ (Fig 5D). These activity and locomotion metrics suggest that the 50:65 ethanol:air dose did not sedate the flies, and that rovers recover from the pharmacological properties of ethanol faster than sitters.

Touching behavior remained higher than baseline levels for all strains $\left(\right.$ for $^{R}(\mathrm{p}=0.02)$, for $^{s}(\mathrm{p}=0.03)$, for $^{s 2}$ $(\mathrm{p}=0.04))$, and was significantly greater in $f \circ r^{R}$ flies than $f o r^{2}(\mathrm{p}=0.01)$ but not for $^{s}$ flies ( $\left.>0.9\right)$ (Fig 5E). for ${ }^{R}$ flies stopping behavior returned to baseline levels $(\mathrm{p}=0.6)$ whereas for $^{s}(\mathrm{p}=0.03)$ and for $^{s 2}(\mathrm{p}=0.03)$ flies continued to show significantly less stopping compared to baseline (Fig 5F). for ${ }^{R}$ flies showed significantly more stops $\left(\mathrm{H}_{(3,19)}=11.93\right.$, $\mathrm{P}=0.0002)$ than for $^{s}(\mathrm{p}=0.003)$ and $f r^{s 2}(\mathrm{p}=0.04)$ flies (Fig $5 \mathrm{~F})$. 
A Conditioning Paradigm

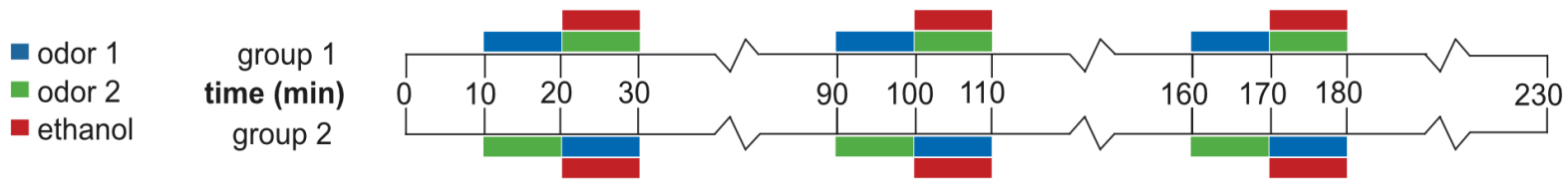

B

\section{Preference Test}
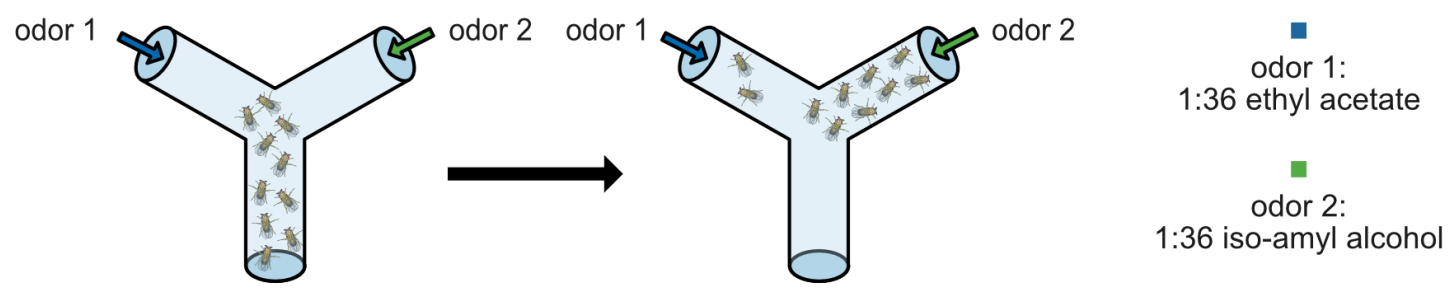

C $30 \mathrm{~min}$ Memory

24 hr Memory
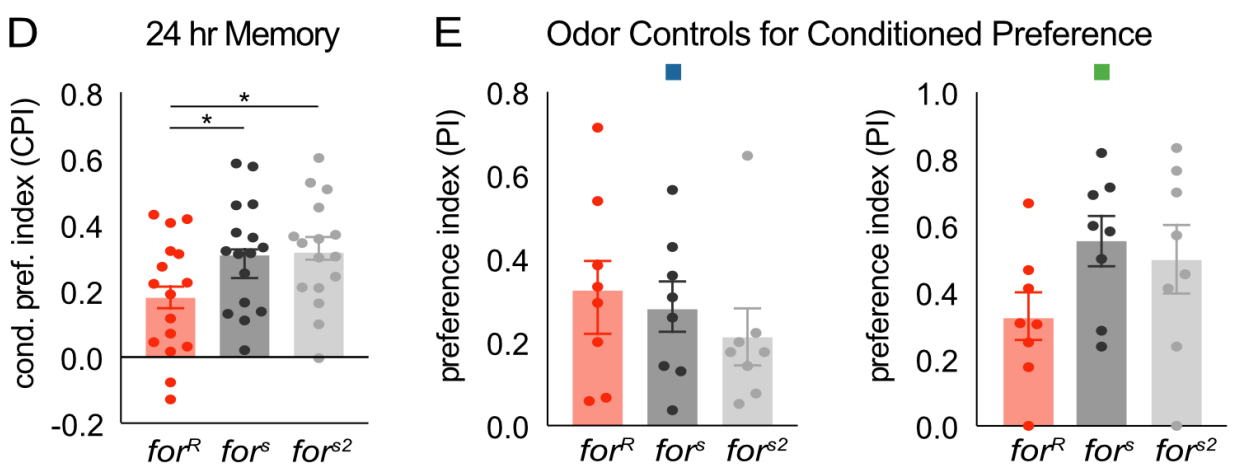

Fig. 6. for affects memory for ethanol reward(A) Flies received 3 training sessions with a 10 min exposure to one odor followed by a 10 min exposure to a second odor paired with $60 \%$ ethanol vapor. Training trials were spaced by 1 hour. A reciprocal group, in which the opposite odor was paired with ethanol, was run. (B) After the training flies were given the choice of the two odors. A preference index was calculated by subtracting the number of flies entering the Odor- vial from the Odor+ vial and dividing this number by the total number of flies. Conditioned preference index was calculated by averaging the preference indexes of the two reciprocal groups. (C) for does not affect conditioned aversion tested 30 min after training. (D) for affects conditioned preference tested 24 hrs. after training. for ${ }^{R}$ flies show decreased memory for ethanol reward compared to for 2 and $f \circ r^{s}$ flies. (E) for does not significantly affect preference for the odors used in the conditioning procedure. $n . s .=p>0.05,{ }^{*}=p<0.05,{ }^{* *}=p<0.01$, ${ }^{* * *}=p>0.001,{ }^{* * * *}=p<0.0001$

\section{foraging affects reward memory for a cue associated} with ethanol. We next hypothesized that the alcohol behavioral sensitivity differences between rovers and sitters would influence how for affects memory for an odor cue associated with ethanol (Fig 6A,B). Typically flies demonstrate aversive memory for ethanol when tested within 9 hours after training, and an appetitive memory when tested 15 hours or more after training (78). Since for has been shown to affect both short-term and long-term memory, we hypothesized that or $^{R}$ would show increased 30-minute aversive memory and reduced 24-hour appetitive memory compared to $f o r^{s}$ and $f o r^{s 2}$. No statistical differences were found between strains when flies were tested 30 minutes after training $\left(\mathrm{H}_{(3,71)}=0.63, \mathrm{P}=0.73\right)$ (Fig 1C). However, 24 hours after training, for ${ }^{R}$ flies show reduced memory for ethanol compared to for $^{s}$ and $f o r^{s 2}$ flies $\left(\mathrm{H}_{(3,71)}=10.27, \mathrm{P}=0.006\right.$, for $^{R}$ vs for $^{s}(\mathrm{p}=0.03)$, for $^{R}$ vs for $\left.{ }^{s 2}(\mathrm{p}=0.002)\right)$ (Fig 1D). No statistical differences were identified in the ability of the strains to smell the odors used in the conditioning assay $\left(\operatorname{IAA}\left(\mathrm{H}_{(3,24)}=3.79, \mathrm{P}=0.15\right), \mathrm{EA}\left(\mathrm{H}_{(3,24)}=1.28, \mathrm{P}=0.53\right)\right)(\mathrm{Fig}$ 1E).

foraging affects ethanol metabolism. Since for affects a number of metabolic phenotypes $(4,14,82)$ we hypothe- sized that the observed behavioral differences between rovers and sitters may stem from the ability to metabolize ethanol differently. Therefore, we tested the internal ethanol levels right after ethanol exposure and after 30 minutes of recovery. We found that $f o r^{R}$ flies absorb ethanol at the similar rate $\left(\mathrm{H}_{(3,27)}=1.87, \mathrm{P}=0.39\right)$ (Fig 7B), but metabolize ethanol faster than for $^{s}$ and for $^{s 2}$ flies $\left(\mathrm{F}(3,20)=13.6, \mathrm{P}<0.0001\right.$, for $^{R}$ vs for $^{s}(\mathrm{p}=0.003)$, for $^{R}$ vs for $\left.{ }^{2}(\mathrm{p}=0.02)\right)($ Fig $7 \mathrm{C})$.

\section{Discussion}

We found that for affects alcohol induced locomotion (pathlength, velocity, activity, and stopping), social behavior (touching), cue-associated memory for the intoxicating properties of ethanol, and ethanol metabolism.

We first recapitulated previously published work demonstrating that rovers move more than sitters in response to a food stimulus. Rovers showed significantly longer pathlength and moved faster compared to the sitter strains in response to a low-dose ethanol odor. This is consistent with previous work describing how rovers walk longer distances while searching for food whereas sitters tend to stay at one food source once they find it (12).

In contrast to these ethologically-relevant ethanol 
Internal Ethanol Concentration Measurment
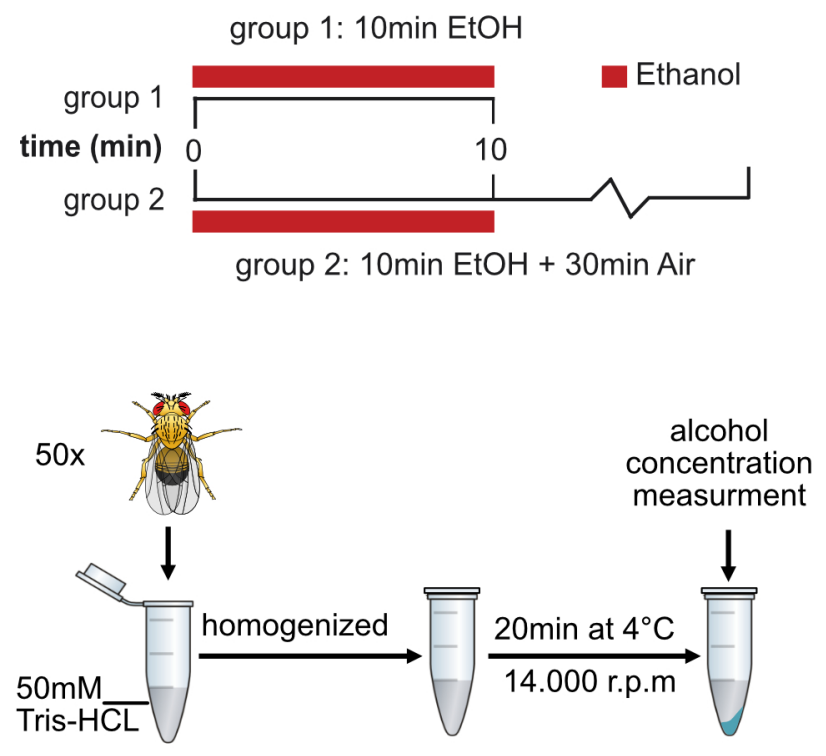

odor responses, we found that a pharmacologically-relevant ethanol concentration induces a sustained increase in the number of flies active within a group of sitters, but not rovers. However, rovers move similar distances and at the same speed as sitters under these conditions. They also touch more often, and stop less than sitters. This suggests that sitters are more sensitive than rovers to pharmacologically relevant stimulating doses of ethanol. This behavioral phenotype is consistent with the slower return to baseline levels after removal of an ethanol stimulus, and with a slower metabolism of ethanol in sitters.

Here we also showed that the foraging gene affects memory for the intoxicating properties of ethanol, since rovers show reduced preference for an ethanol associated odor cue 24 hours after the association. This is consistent with known roles of for in learning and memory. Rover larvae are better able to acquire and remember three but not eight odor-sucrose pairings compared to sitter larvae (82). Similarly, adult rover flies have better short-term olfactory memory, but worse long-term olfactory memory than sitters (28). This phenotypic difference is also seen in visual learning paradigms and is conserved in mammals $(83,84)$. Rovers also show higher retroactive interference, which occurs when the retrieval of previously learned information is less available owing to the acquisition of recently acquired information $(27,29,30)$.

In the case of ethanol reward memory in Drosophila, we speculate that the difference in ethanol sensitivity between for strains alters perception of the intoxicating experience, causing reward to be processed differently in rovers and sitters. This may explain why for does not affect aversive short-term memory for ethanol, as this type of memory is not dependent on intoxicating concentrations of

\section{B 10min EtOH Exposure}
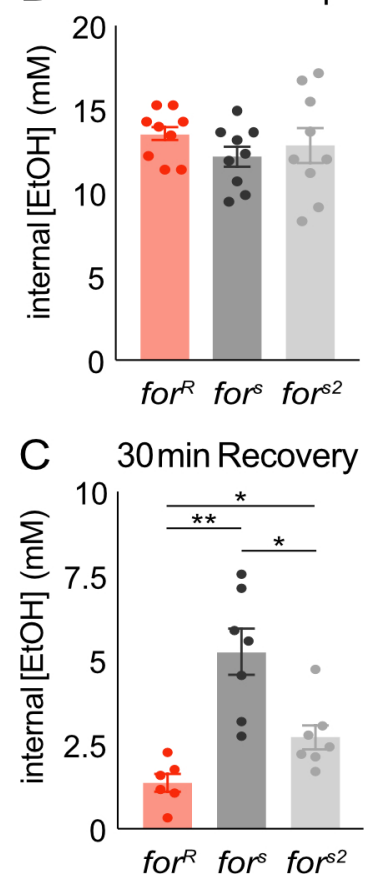

Fig. 7. for affects ethanol metabolism(A) Flies received a 10 min exposure to $60 \%$ ethanol in perforated vials in the training boxes used for ethanol memory. Flies from Group One were frozen immediately in liquid nitrogen, flies from group two are exposed to air for another $30 \mathrm{~min}$. Flies were homogenized in $500 \mu$ of cold $50 \mathrm{mM}$ Tris- $\mathrm{HCl}(\mathrm{pH}$ 7.5 , Sigma) and the homogenate was centrifuged at 14,000 r.p.m. for 20 min at $4{ }^{\circ} \mathrm{C}$. Ethanol concentrations in supernatants were measured using an alcohol dehydrogenase-based spectrophotometric assay (Ethanol Assay Kit 229-29, Diagnostic Chemicals). To calculate fly internal ethanol concentration, the volume of one fly was estimated to be 2 $\mu l$. (B) for does not affect ethanol absorption. (C) for affects rate of recovery from ethanol exposure. for ${ }^{R}$ flies metabolize ethanol faster than for $r^{s}$ and for $^{s 2}$ flies. n.s. $=\mathrm{p}>0.05$, ${ }^{*}=p<0.05, \quad{ }^{* *}=p<0.01, \quad{ }^{* * *}=p>0.001$, $* * * *=p<0.0001$ ethanol (79). Since for affects sensitivity to sucrose and other food substances, altering perception of the reward stimulus may be a more general mechanism through which PKG influences alcohol preference $(3,75)$.

Alternatively, as for also affects alcohol-induced increases in activity, this change in behavior could be affecting memory acquisition independent of reward perception. Notably, for would not affect the behavioral choice during the memory test since the flies are no longer intoxicated during odor choice (Fig 6A) and for does not appear to significantly affect preference for the odors used (Fig 6E).

Ethanol sensitivity has been associated with greater consumption and risk for developing an AUD (85-87). In human and rodents, sensitivity to the effects of alcohol intoxication is partially influenced by genes, whereas reduced sensitivity predicts the development of alcoholism (88-90). Thus, both heightened alcohol stimulation and reward sensitivity, and lower sensitivity to alcohol sedation robustly predicts more AUD symptoms over time in humans (86, 90). Studies in Drosophila recapitulate this, where genes influence the level of response to an intoxicating dose of ethanol (62, 91-94). Genome-wide association studies (GWAS) for alcohol sensitivity using the sequenced, inbred lines of the Drosophila genetic reference panel (DGRP) together with quantitative trait locus (QTL) mapping in an advanced intercross outbred population derived from sensitive and resistant DGRP lines, revealed 247 candidate genes affecting alcohol sensitivity, 58 of which, including the foraging gene, form a genetic interaction network (95).

Notably, our work did not demonstrate a consistent effect of for on touching. Although we observed a small trend where rovers demonstrated increased touching compared to sitters in the high-ethanol context (Fig 4E), this trend was not 
bioRxiv preprint doi: https://doi.org/10.1101/2021.02.09.430533; this version posted February 10, 2021. The copyright holder for this preprint (which was not certified by peer review) is the author/funder, who has granted bioRxiv a license to display the preprint in perpetuity. It is made available under aCC-BY-NC 4.0 International license.

observed in any other behavioral contexts. Relatedly, for affected locomotion in the presence of a food odor in a similar way in our group assay as it did when flies are isolated in previously published studies $(10,12)$. Our lack of findings here was surprising as for affects social behaviors including aggregation behavior (96) and aggression (97), and influences behaviors that are dependent on a social context such as olfactory learning (98), and oviposition (99). Similarly, for orthologues influence social behaviors in other taxa including bees (100-102), wasps (103) and ants $(104,105)$. Our results failed to demonstrate an observed decrease in social dynamics in rovers compared to sitters that was recently observed in a similar assay (106). We speculate that sensory cues necessary for spontaneous social behaviors may have been obscured in our paradigm by a constant flow of hydrated air or odors through the behavioral chambers. This suggests that our behavioral paradigm was not optimal for identifying how for affected social behavior, or how social context could influence for-dependent behaviors.

Taken together, the work here contributes to a mechanistic understanding of alcohol sensitivity as indication for AUD by demonstrating how natural variation in metabolic phenotypes can impact behavioral response to an addictive substance. Our data predict that variants of for with lower PKG activity in other species will show increased ethanol sensitivity, and increased lasting ethanol preference.

This is consistent with results on the role of PKG in ethanol-induced behaviors from rodent models, suggesting the effects of PKG on alcohol behaviors are highly conserved. cGMP-dependent protein kinase type II (cGKII) knockout mice showed elevated alcohol preference in a 2-bottle free choice test (44), demonstrating that reduction in PKG is associated with increased alcohol preference in both mice and flies. Moreover, cGMP activates NO, which inhibits dopamine release in the striatum in rats resulting in decreasing reward response for alcohol $(43,49)$. These studies are consistent with rovers showing decreased ethanol preference, as they have higher PKG activity than sitters. Whether this is the mechanism through which variation in PRKG1 increases risk for alcohol abuse in humans remains to be seen $(39,40)$.

\section{Declaration of Interest}

The authors declare no conflict of interest

\section{ACKNOWLEDGEMENTS}

We would like to thank Dr. Ulrike Heberlein (Janelia Research Campus) for helpful early discussions about the alcohol-associated preference and metabolism data. Thanks to Dr. Kristin Branson (Janelia Research Campus), Dr. Alice Robie (Janelia Research Campus), Dr. Mayank Kabra (Janelia Research Campus) and members of the Ctrax and JAABA google groups for ongoing assistance with Ctrax and JAABA. Thanks to members of the Kaun Lab and Dr. Kristin Scaplen (Bryant University) for providing helpful feedback on data visualization, analysis, and writing. Thanks to Dr. Marla Sokolowski for providing the for strains. This work was funded by the National Institutes of Health (R01AA024434 to K.R.K).

With gratitude to Dr. Marla Sokolowski:

Thanks especially to Dr. Marla Sokolowski (University of Toronto), whose guidance was integral to the conceptualization of this work. It is the people that we work with, including incredible mentors like Marla, that help shape us as scientists. Marla has been a huge inspiration to me (Karla), and more broadly an entire generation of behavioral geneticists. Her contributions have made an important and indelible mark on the field. I'm extremely grateful to her for her rigorous scientific training and continued patience, encouragement and immense knowledge. Marla is a lifelong mentor, and I consider myself incredibly fortunate to have the opportunity to conduct a study related to her research in my own lab. This work was completed with immense gratitude to Marla, for setting the stage and making it possible for generations of scientists to use foraging as an example of how natural genetic variation affects behavior. We all thank-you Marla, for being the amazing mentor and scientist that you are.

\section{Bibliography}

1. M. B. Sokolowski. Foraging strategies of Drosophila melanogaster: A chromosomal analysis. Behavior Genetics, 10(3):291-302, may 1980. ISSN 0001-8244. doi: 10.1007/ BF01067774.

2. KA Osborne, A Robichon, E Burgess, S Butland, RA Shaw, A Coulthard, HS Pereira, RJ Greenspan, and MB Sokolowski. Natural behavior polymorphism due to a cgmpdependent protein kinase of drosophila. Science, 277(5327):834-836, 1997.

3. Bryon N. Hughson, Ina Anreiter, Nicholas L. Jackson Chornenki, Keith R. Murphy, William W. Ja, Robert Huber, and Marla B. Sokolowski. The adult foraging assay (AFA) detects strain and food-deprivation effects in feeding-related traits of Drosophila melanogaster. Journal of Insect Physiology, 106:20-29, apr 2018. ISSN 00221910. doi: 10.1016/j.jinsphys.2017.08.011.

4. A. M. Allen, I. Anreiter, A. Vesterberg, S. J. Douglas, and M. B. Sokolowski. Pleiotropy of the Drosophila melanogaster foraging gene on larval feeding-related traits. Journal of Neurogenetics, 32(3):256-266, jul 2018. ISSN 0167-7063. doi: 10.1080/01677063.2018. 1500572 .

5. James B. Brown, Nathan Boley, Robert Eisman, Gemma E. May, Marcus H. Stoiber, Michael O. Duff, Ben W. Booth, Jiayu Wen, Soo Park, Ana Maria Suzuki, Kenneth H. Wan, Charles Yu, Dayu Zhang, Joseph W. Carlson, Lucy Cherbas, Brian D. Eads, David Miller, Keithanne Mockaitis, Johnny Roberts, Carrie A. Davis, Erwin Frise, Ann S. Hammonds, Sara Olson, Sol Shenker, David Sturgill, Anastasia A. Samsonova, Richard Weiszmann, Garret Robinson, Juan Hernandez, Justen Andrews, Peter J. Bickel, Piero Carninci, Peter Cherbas, Thomas R. Gingeras, Roger A. Hoskins, Thomas C. Kaufman, Eric C. Lai, Brian Oliver, Norbert Perrimon, Brenton R. Graveley, and Susan E. Celniker. Diversity and dynamics of the Drosophila transcriptome. Nature, 512(7515):393-399, aug 2014. ISSN 0028-0836. doi: 10.1038/nature12962.

6. Brenton R. Graveley, Angela N. Brooks, Joseph W. Carlson, Michael O. Duff, Jane M. Landolin, Li Yang, Carlo G. Artieri, Marijke J. van Baren, Nathan Boley, Benjamin W. Booth, James B. Brown, Lucy Cherbas, Carrie A. Davis, Alex Dobin, Renhua Li, Wei Lin, John H. Malone, Nicolas R. Mattiuzzo, David Miller, David Sturgill, Brian B. Tuch, Chris Zaleski, Dayu Zhang, Marco Blanchette, Sandrine Dudoit, Brian Eads, Richard E. Green, Ann Hammonds, Lichun Jiang, Phil Kapranov, Laura Langton, Norbert Perrimon, Jeremy E. Sandler, Kenneth H. Wan, Aarron Willingham, Yu Zhang, Yi Zou, Justen Andrews, Peter J. Bickel, Steven E. Brenner, Michael R. Brent, Peter Cherbas, Thomas R. Gingeras, Roger A. Hoskins, Thomas C. Kaufman, Brian Oliver, and Susan E. Celniker. The developmental transcriptome of Drosophila melanogaster. Nature, 471(7339):473-479, mar 2011. ISSN 0028-0836. doi: 10.1038/nature09715.

7. Nicolas Nègre, Christopher D. Brown, Lijia Ma, Christopher Aaron Bristow, Steven W. Miller, Ulrich Wagner, Pouya Kheradpour, Matthew L. Eaton, Paul Loriaux, Rachel Sealfon, Zirong Li, Haruhiko Ishii, Rebecca F. Spokony, Jia Chen, Lindsay Hwang, Chao Cheng, Richard P. Auburn, Melissa B. Davis, Marc Domanus, Parantu K. Shah, Carolyn A. Morrison, Jennifer Zieba, Sarah Suchy, Lionel Senderowicz, Alec Victorsen, Nicholas A. Bild, A. Jason Grundstad, David Hanley, David M. MacAlpine, Mattias Mannervik, Koen Venken, Hugo Bellen, Robert White, Mark Gerstein, Steven Russell, Robert L. Grossman, Bing Ren, James W. Posakony, Manolis Kellis, and Kevin P. White. A cis-regulatory map of the Drosophila genome. Nature, 471(7339):527-531, mar 2011. ISSN 0028-0836. doi: 10.1038/nature09990.

8. Ina Anreiter, Jamie M. Kramer, and Marla B. Sokolowski. Epigenetic mechanisms modulate differences in Drosophila foraging behavior. Proceedings of the National Academy of Sciences, 114(47):12518-12523, nov 2017. ISSN 0027-8424. doi: 10.1073/pnas. 1710770114 .

9. Ina Anreiter, H. Moriah Sokolowski, and Marla B. Sokolowski. Gene-Environment Interplay and Individual Differences in Behavior. Mind, Brain, and Education, 12(4):200-211, dec 2018. ISSN 1751-2271. doi: 10.1111/mbe.12158.

10. H Sofia Pereira and Marla B Sokolowski. Mutations in the larval foraging gene affect adult locomotory behavior after feeding in Drosophila melanogaster. Proceedings of the National Academy of Sciences, 90(11):5044-5046, jun 1993. ISSN 0027-8424. doi: 10.1073/pnas. 90.11.5044.

11. J S de Belle, A J Hilliker, and Marla B Sokolowski. Genetic localization of foraging (for): a major gene for larval behavior in Drosophila melanogaster. Genetics, 123(1):157-63, sep 1989. ISSN 0016-6731.

12. J Steven de Belle and Marla B Sokolowski. Heredity of rover/sitter: Alternative foraging strategies of Drosophila melanogaster larvae. Heredity, 59(1):73-83, aug 1987. ISSN 0018-067X. doi: 10.1038/hdy.1987.98.

13. AM Allen, I Anreiter, A Vesterberg, SJ Douglas, and MB Sokolowski. Pleiotropy of the drosophila melanogaster foraging gene on larval feeding-related traits. Journal of neurogenetics, 32(3):256-266, 2018.

14. Karla R. Kaun, Munmun Chakaborty-Chatterjee, and Marla B. Sokolowski. Natural variation in plasticity of glucose homeostasis and food intake. Journal of Experimental Biology, 211(19):3160-3166, oct 2008. ISSN 0022-0949. doi: 10.1242/jeb.010124.

15. Aaron M Allen, Ina Anreiter, Megan C Neville, and Marla B Sokolowski. Feeding-Related Traits Are Affected by Dosage of the foraging Gene in Drosophila melanogaster. Genetics, 205(2):761-773, feb 2017. ISSN 0016-6731. doi: 10.1534/genetics.116.197939. 
bioRxiv preprint doi: https://doi.org/10.1101/2021.02.09.430533; this version posted February 10, 2021. The copyright holder for this preprint

(which was not certified by peer review) is the author/funder, who has granted bioRxiv a license to display the preprint in perpetuity. It is made available under aCC-BY-NC 4.0 International license.

16. A.T. Belay, R. Scheiner, A.K.-C. So, S.J. Douglas, M. Chakaborty-Chatterjee, J.D. Levine, and M.B. Sokolowski. Theforaging gene ofDrosophila melanogaster: Spatial-expression analysis and sucrose responsiveness. The Journal of Comparative Neurology, 504(5): 570-582, oct 2007. ISSN 00219967. doi: 10.1002/cne.21466.

17. Ricarda Scheiner, Marla B. Sokolowski, and Joachim Erber. Activity of cGMP-Dependent Protein Kinase (PKG) Affects Sucrose Responsiveness and Habituation in Drosophila melanogaster. Learning \& Memory, 11(3):303-311, may 2004. ISSN 1072-0502. doi: 10.1101/lm.71604.

18. Jeffrey Donlea, Averi Leahy, Matthew S Thimgan, Yasuko Suzuki, Bryon N Hughson, Marla B Sokolowski, and Paul J Shaw. foraging alters resilience/vulnerability to sleep disruption and starvation in Drosophila. Proceedings of the National Academy of Sciences, 109(7):2613-2618, feb 2012. ISSN 0027-8424. doi: 10.1073/pnas.1112623109.

19. Mark Eddison, Amsale T. Belay, Marla B. Sokolowski, and Ulrike Heberlein. A Genetic Screen for Olfactory Habituation Mutations in Drosophila: Analysis of Novel Foraging Alleles and an Underlying Neural Circuit. PLoS ONE, 7(12):e51684, dec 2012. ISSN 19326203. doi: 10.1371/journal.pone.0051684.

20. Jeff E Engel, Xian-Jin Xie, Marla B Sokolowski, and Chun-Fang Wu. A cGMP-Dependent Protein Kinase Gene, foraging, Modifies Habituation-Like Response Decrement of the Giant Fiber Escape Circuit in Drosophila. Learning \& Memory ., 7(5):341-352, 2000. doi: 10.1101/lm.31600

21. Jeffrey S Dason, Amanda Cheung, Ina Anreiter, Vanessa A Montemurri, Aaron M Allen, and Marla B Sokolowski. Drosophila melanogaster foraging regulates a nociceptive-like escape behavior through a developmentally plastic sensory circuit. Proceedings of the National Academy of Sciences, 117(38):23286-23291, sep 2020. ISSN 0027-8424. doi: $10.1073 /$ pnas. 1820840116 .

22. Murray W. McConnell and Mark J. Fitzpatrick. 'Foraging' for a place to lay eggs: A genetic link between foraging behaviour and oviposition preferences. PLOS ONE, 12(6): e0179362, jun 2017. ISSN 1932-6203. doi: 10.1371/journal.pone.0179362.

23. Stacee Lee Caplan, Sarah L. Milton, and Ken Dawson-Scully. A cGMP-dependent protein kinase (PKG) controls synaptic transmission tolerance to acute oxidative stress at the Drosophila larval neuromuscular junction. Journal of Neurophysiology, 109(3):649-658, feb 2013. ISSN 0022-3077. doi: 10.1152/jn.00784.2011.

24. K Dawson-Scully, D Bukvic, M. Chakaborty-Chatterjee, R. Ferreira, S. L. Milton, and M. B. Sokolowski. Controlling anoxic tolerance in adult Drosophila via the cGMP-PKG pathway. Journal of Experimental Biology, 213(14):2410-2416, jul 2010. ISSN 0022-0949. doi: 10.1242/jeb.041319.

25. Ken Dawson-Scully, Gary A.B. B. Armstrong, Clement Kent, R. Meldrum Robertson, and Maria B. Marla B. Sokolowski. Natural Variation in the Thermotolerance of Neural Function and Behavior due to a cGMP-Dependent Protein Kinase. PLOS ONE, 2(8):e773, aug 2007. ISSN 1932-6203. doi: 10.1371/journal.pone.0000773.

26. Karla R Kaun, Thomas Hendel, Bertram Gerber, and Marla B Sokolowski. Natural variation in Drosophila larval reward learning and memory due to a cGMP-dependent protein kinase. Learning \& Memory, 14(5):342-349, may 2007. ISSN 1072-0502. doi: 10.1101/lm.505807.

27. Sara Kuntz, Burkhard Poeck, Marla B Sokolowski, and Roland Strauss. The visual orientation memory of Drosophila requires Foraging (PKG) upstream of Ignorant (RSK2) in ring neurons of the central complex. Learning \& Memory, 19(8):337-340, jul 2012. ISSN 1072-0502. doi: 10.1101//m.026369.112.

28. Frederic Mery, Amsale T Belay, Anthony K-C So, Marla B Sokolowski, and Tadeusz $J$ Kawecki. Natural polymorphism affecting learning and memory in Drosophila. Proceedings of the National Academy of Sciences, 104(32):13051-13055, aug 2007. ISSN 0027-8424. doi: 10.1073/pnas.0702923104.

29. Christopher J. Reaume, Marla B. Sokolowski, and Frederic Mery. A natural genetic polymorphism affects retroactive interference in Drosophila melanogaster. Proceedings of the Royal Society B: Biological Sciences, 278(1702):91-98, jan 2011. ISSN 0962-8452. doi: 10.1098/rspb.2010.1337.

30. Zhipeng Wang, Yufeng Pan, Weizhe Li, Huoqing Jiang, Lazaros Chatzimanolis, Jianhong Chang, Zhefeng Gong, and Li Liu. Visual pattern memory requires foraging function in the central complex of Drosophila. Learning \& Memory, 15(3):133-142, feb 2008. ISSN 1072-0502. doi: 10.1101/lm.873008.

31. K Heylen, B Gobin, J Billen, TT Hu, L. Arckens, and R. Huybrechts. Amfor expression in the honeybee brain: A trigger mechanism for nurse-forager transition. Journal of Insect Physiology, 54(10-11):1400-1403, oct 2008. ISSN 00221910. doi: 10.1016/j.jinsphys. 2008.07.015.

32. R Meldrum Robertson and Keith T Sillar. The Nitric Oxide/cGMP Pathway Tunes the Thermosensitivity of Swimming Motor Patterns in Xenopus laevis Tadpoles. Journal of Neuroscience, 29(44):13945-13951, nov 2009. ISSN 0270-6474. doi: 10.1523/JNEUROSCI. 3841-09.2009.

33. Gary A.B. Armstrong, Juan J. López-Guerrero, Ken Dawson-Scully, Fernando Peña, and R. Meldrum Robertson. Inhibition of protein kinase $G$ activity protects neonatal mouse respiratory network from hyperthermic and hypoxic stress. Brain Research, 1311:64-72, jan 2010. ISSN 00068993. doi: 10.1016/j.brainres.2009.11.038.

34. Manabi Fujiwara, Piali Sengupta, and Steven L. McIntire. Regulation of Body Size and Behavioral State of C. elegans by Sensory Perception and the EGL-4 cGMP-Dependent Protein Kinase. Neuron, 36(6):1091-1102, dec 2002. ISSN 08966273. doi: 10.1016/ S0896-6273(02)01093-0.

35. David M. Raizen, John E. Zimmerman, Matthew H. Maycock, Uyen D. Ta, Young-jai You, Meera V. Sundaram, and Allan I. Pack. Lethargus is a Caenorhabditis elegans sleep-like state. Nature, 451(7178):569-572, jan 2008. ISSN 0028-0836. doi: 10.1038/nature06535.

36. H. Moriah Sokolowski, Oscar E. Vasquez, Eva Unternaehrer, Dustin J. Sokolowski, Stephanie D Biergans, Leslie Atkinson, Andrea Gonzalez, Patricia P. Silveira, Robert Levitan, Kieran J. O'Donnell, Meir Steiner, James Kennedy, Michael J. Meaney, Alison S. Fleming, and Marla B. Sokolowski. The Drosophila foraging gene human orthologue PRKG1 predicts individual differences in the effects of early adversity on maternal sensitivity. Cognitive Development, 42:62-73, apr 2017. ISSN 08852014. doi: 10.1016/j.cogdev.2016.11.001.
37. Andriy A. Struk, Jhotisha Mugon, Andrea Huston, Abigail A. Scholer, Gertraud Stadler, E Tory Higgins, Marla B. Sokolowski, and James Danckert. Self-regulation and the foraging gene ( PRKG1) in humans. Proceedings of the National Academy of Sciences, 116(10): 4434-4439, mar 2019. ISSN 0027-8424. doi: 10.1073/pnas.1809924116.

38. Yanhui Hu, Ian Flockhart, Arunachalam Vinayagam, Clemens Bergwitz, Bonnie Berger, Norbert Perrimon, and Stephanie E Mohr. An integrative approach to ortholog prediction for disease-focused and other functional studies. BMC Bioinformatics, 12(1):357, 2011. ISSN 1471-2105. doi: 10.1186/1471-2105-12-357.

39. Sage E. Hawn, Christina M. Sheerin, Bradley T. Webb, Roseann E. Peterson, Elizabeth K. Do, Danielle Dick, Kenneth S. Kendler, Silviu-Alin Bacanu, and Ananda B. Amstadter. Replication of the Interaction of PRKG1 and Trauma Exposure on Alcohol Misuse in an Independent African American Sample. Journal of Traumatic Stress, 31(6):927-932, dec 2018. ISSN 0894-9867. doi: 10.1002/jts. 22339.

40. R. Polimanti, J. Kaufman, H. Zhao, H. R. Kranzler, R. J. Ursano, R. C. Kessler, J. Gelernter, and M. B. Stein. A genome-wide gene-by-trauma interaction study of alcohol misuse in two independent cohorts identifies PRKG1 as a risk locus. Molecular Psychiatry, 23(1):154160, jan 2018. ISSN 1359-4184. doi: 10.1038/mp.2017.24.

41. Allison E. Ashley-Koch, Melanie E. Garrett, Jason Gibson, Yutao Liu, Michelle F. Dennis, Nathan A. Kimbrel, Jean C. Beckham, and Michael A. Hauser. Genome-wide association study of posttraumatic stress disorder in a cohort of Iraq-Afghanistan era veterans. Journal of Affective Disorders, 184:225-234, sep 2015. ISSN 01650327. doi: 10.1016/j.jad.2015. 03.049.

42. I.Tayfun Uzbay, Turgay Celik, Ahmet Aydın, Hakan Kayir, Serhat Tokgöz, and Cumhur Bilgi. Effects of chronic ethanol administration and ethanol withdrawal on cyclic guanosine 3,5-monophosphate (cGMP) levels in the rat brain. Drug and Alcohol Dependence, 74(1): 55-59, apr 2004. ISSN 03768716. doi: 10.1016/j.drugalcdep.2003.11.011.

43. Pascal Romieu, Serge Gobaille, Dominique Aunis, and Jean Zwiller. Injection of the Neuropeptide CNP into Dopaminergic Rat Brain Areas Decreases Alcohol Intake. Annals of the New York Academy of Sciences, 1139(1):27-33, oct 2008. ISSN 00778923. doi: 10.1196/annals. 1432.050.

44. Claudia Werner, Gennadij Raivich, Michael Cowen, Tatyana Strekalova, Inge Sillaber, Jeroen T. Buters, Rainer Spanagel, and Franz Hofmann. Importance of NO/cGMP signalling via cGMP-dependent protein kinase II for controlling emotionality and neurobehavioural effects of alcohol. European Journal of Neuroscience, 20(12):3498-3506, dec 2004. ISSN 0953-816X. doi: 10.1111/j.1460-9568.2004.03793.x.

45. Thomas Kleppisch and Robert Feil. cGMP Signalling in the Mammalian Brain: Role in Synaptic Plasticity and Behaviour. In Handbook of Experimental Pharmacology, volume 191, pages 549-579. 2009. ISBN 9783540689607. doi: 10.1007/978-3-540-68964-5_24.

46. John J. Renger, Wei-Dong Yao, Marla B. Sokolowski, and Chun-Fang Wu. Neuronal Polymorphism among Natural Alleles of a cGMP-Dependent Kinase Gene, foraging , in Drosophila. The Journal of Neuroscience, 19(19):RC28-RC28, oct 1999. ISSN 02706474. doi: 10.1523/JNEUROSCI.19-19-j0002.1999.

47. Rui-Ting Wen, Fang-Fang Zhang, and Han-Ting Zhang. Cyclic nucleotide phosphodiesterases: potential therapeutic targets for alcohol use disorder. Psychopharmacology, 235(6):1793-1805, jun 2018. ISSN 0033-3158. doi: 10.1007/s00213-018-4895-7.

48. Ying Xu, Jianchun Pan, Jiao Sun, Lianshu Ding, Lina Ruan, Miranda Reed, Xuefeng Yu, Jonathan Klabnik, Dan Lin, Jianxin Li, Ling Chen, Chong Zhang, Hanting Zhang, and James M. O'Donnell. Inhibition of phosphodiesterase 2 reverses impaired cognition and neuronal remodeling caused by chronic stress. Neurobiology of Aging, 36(2):955-970, feb 2015. ISSN 01974580. doi: 10.1016/j.neurobiolaging.2014.08.028.

49. Rosalinda Guevara-Guzman, Piers C. Emson, and Keith M. Kendrick. Modulation of In Vivo Striatal Transmitter Release by Nitric Oxide and Cyclic GMP. Journal of Neurochemistry, 62(2):807-810, nov 2002. ISSN 00223042. doi: 10.1046/j.1471-4159.1994.62020807.x.

50. Willis K. Samson, Renee Bianchi, and Randy Mogg. Evidence for a Dopaminergic Mechanism for the Prolactin Inhibitory Effect of Atrial Natriuretic Factor. Neuroendocrinology, 47 (3):268-271, 1988. ISSN 0028-3835. doi: 10.1159/000124922.

51. Nathalie Thiriet, Peggy Jouvert, Serge Gobaille, Olga Solov'Eva, Bobby Gough, Dominique Aunis, Syed Ali, and Jean Zwiller. C-type natriuretic peptide (CNP) regulates cocaine-induced dopamine increase and immediate early gene expression in rat brain. European Journal of Neuroscience, 14(10):1702-1708, nov 2001. ISSN 0953816X. doi: 10.1046/j.0953-816x.2001.01791.x.

52. Elodie Deschatrettes, Pascal Romieu, and Jean Zwiller. Cocaine self-administration by rats is inhibited by cyclic GMP-elevating agents: involvement of epigenetic markers. International Journal of Neuropsychopharmacology, 16(7):1587-1597, aug 2013. ISSN 14695111. doi: 10.1017/S1461145712001630.

53. Fereshteh S. Nugent, Esther C. Penick, and Julie A. Kauer. Opioids block long-term potentiation of inhibitory synapses. Nature, 446(7139):1086-1090, apr 2007. ISSN 0028-0836. doi: 10.1038/nature05726

54. Gregory L. Engel, Kreager Taber, Elizabeth Vinton, and Amanda J. Crocker. Studying alcohol use disorder using Drosophila melanogaster in the era of 'Big Data'. Behavioral and Brain Functions, 15(1):7, dec 2019. ISSN 1744-9081. doi: 10.1186/s12993-019-0159-x.

55. Annie Park, Alfredo Ghezzi, Thilini P. Wijesekera, and Nigel S. Atkinson. Genetics and genomics of alcohol responses in Drosophila. Neuropharmacology, 122:22-35, aug 2017. ISSN 00283908. doi: 10.1016/j.neuropharm.2017.01.032.

56. Emily Petruccelli and Karla R. Kaun. Insights from intoxicated Drosophila, feb 2019. ISSN 18736823.

57. Summer F Acevedo, Dante A Gonzalez, Aylin R Rodan, Adrian Rothenfluh, et al. S6 kinase reflects and regulates ethanol-induced sedation. Journal of Neuroscience, 35(46): 15396-15402, 2015

58. Andrew R. Butts, Shamsideen A. Ojelade, Eva D. Pronovost, Alexandra Seguin, Collin B. Merrill, Aylin R. Rodan, and Adrian Rothenfluh. Altered Actin Filament Dynamics in the Drosophila Mushroom Bodies Lead to Fast Acquisition of Alcohol Consumption Preference. The Journal of Neuroscience, 39(45):8877-8884, nov 2019. ISSN 0270-6474. doi: 10.1523/JNEUROSCI.0973-19.2019.

59. Gerbera Claßen and Henrike Scholz. Octopamine Shifts the Behavioral Response From Indecision to Approach or Aversion in Drosophila melanogaster. Frontiers in Behavioral 
bioRxiv preprint doi: https://doi.org/10.1101/2021.02.09.430533; this version posted February 10, 2021. The copyright holder for this preprint (which was not certified by peer review) is the author/funder, who has granted bioRxiv a license to display the preprint in perpetuity. It is made available under aCC-BY-NC 4.0 International license.

Neuroscience, 12, jul 2018. ISSN 1662-5153. doi: 10.3389/fnbeh.2018.00131.

60. Alfredo Ghezzi, Yazan M. Al-Hasan, Harish R. Krishnan, Yan Wang, and Nigel S. Atkinson. Functional Mapping of the Neuronal Substrates for Drug Tolerance in Drosophila. Behavior Genetics, 43(3):227-240, may 2013. ISSN 0001-8244. doi: 10.1007/s10519-013-9583-0.

61. Alfredo Ghezzi, Harish R. Krishnan, Linda Lew, Francisco J. Prado, Darryl S. Ong, and Nigel S. Atkinson. Alcohol-Induced Histone Acetylation Reveals a Gene Network Involved in Alcohol Tolerance. PLoS Genetics, 9(12):e1003986, dec 2013. ISSN 1553-7404. doi: 10.1371/journal.pgen.1003986.

62. Eric C. Kong, Lorien Allouche, Paul A. Chapot, Karen Vranizan, Monica S. Moore, Ulrike Heberlein, and Fred W. Wolf. Ethanol-Regulated Genes That Contribute to Ethanol Sensitivity and Rapid Tolerance in Drosophila. Alcoholism: Clinical and Experimental Research, 34(2):302-316, feb 2010. ISSN 01456008. doi: 10.1111/j.1530-0277.2009.01093.x.

63. Daniel R. Lathen, Collin B. Merrill, and Adrian Rothenfluh. Flying Together: Drosophila as a Tool to Understand the Genetics of Human Alcoholism. International Journal of Molecular Sciences, 21(18):6649, sep 2020. ISSN 1422-0067. doi: 10.3390/ijms21186649.

64. Kristen M. Lee, Laura D. Mathies, and Mike Grotewiel. Alcohol sedation in adult Drosophila is regulated by Cysteine proteinase-1 in cortex glia. Communications Biology, 2(1):252, dec 2019. ISSN 2399-3642. doi: 10.1038/s42003-019-0492-5.

65. Shamsideen A. Ojelade, Tianye Jia, Aylin R. Rodan, Tao Chenyang, Julie L. Kadrmas, Anna Cattrell, Barbara Ruggeri, Pimphen Charoen, Hervé Lemaitre, Tobias Banaschewski, Christian Büchel, Arun L. W. Bokde, Fabiana Carvalho, Patricia J. Conrod, Herta Flor, Vincent Frouin, Jürgen Gallinat, Hugh Garavan, Penny A. Gowland, Andreas Heinz, Bernd Ittermann, Mark Lathrop, Steven Lubbe, Jean-Luc Martinot, Tomás Paus, Michael N. Smolka, Rainer Spanagel, Paul F. O'Reilly, Jaana Laitinen, Juha M. Veijola, Jianfeng Feng, Sylvane Desrivières, Marjo-Riitta Jarvelin, Gunter Schumann, and Adrian Rothenfluh. Rsu1 regulates ethanol consumption in Drosophila and humans. Proceedings of the National Academy of Sciences, 112(30):E4085-E4093, jul 2015. ISSN 0027-8424. doi: 10.1073/pnas.1417222112

66. Sarah J. Parkhurst, Pratik Adhikari, Jovana S. Navarrete, Arièle Legendre, Miguel Manansala, and Fred W. Wolf. Perineurial Barrier Glia Physically Respond to Alcohol in an Akap200-Dependent Manner to Promote Tolerance. Cell Reports, 22(7):1647-1656, feb 2018. ISSN 22111247. doi: 10.1016/j.celrep.2018.01.049.

67. Emily Petruccelli, Michael Feyder, Nicolas Ledru, Yanabah Jaques, Edward Anderson and Karla R. Kaun. Alcohol Activates Scabrous-Notch to Influence Associated Memories. Neuron, 100(5):1209-1223.e4, dec 2018. ISSN 08966273. doi: 10.1016/j.neuron.2018.10. 005

68. Jorge H. Pinzón, Addison R. Reed, Nevine A. Shalaby, Michael Buszczak, Aylin R. Rodan, and Adrian Rothenfluh. Alcohol-Induced Behaviors Require a Subset of Drosophila JmjCDomain Histone Demethylases in the Nervous System. Alcoholism: Clinical and Experimental Research, 41(12):2015-2024, dec 2017. ISSN 01456008. doi: 10.1111/acer.13508.

69. Aylin R. Rodan and Adrian Rothenfluh. The Genetics of Behavioral Alcohol Responses in Drosophila. pages 25-51. 2010. doi: 10.1016/S0074-7742(10)91002-7.

70. Kristin M. Scaplen, Nicholas J. Mei, Hayley A. Bounds, Sophia L. Song, Reza Azanchi, and Karla R. Kaun. Automated real-time quantification of group locomotor activity in Drosophila melanogaster. Scientific Reports, 9(1):4427, dec 2019. ISSN 2045-2322. doi: 10.1038/ s41598-019-40952-5.

71. Kristin M Scaplen, Mustafa Talay, Kavin M Nunez, Sarah Salamon, Amanda G Waterman, Sydney Gang, Sophia L Song, Gilad Barnea, and Karla R Kaun. Circuits that encode and guide alcohol-associated preference. eLife, 9, jun 2020. ISSN 2050-084X. doi: 10.7554/ eLife. 48730 .

72. Nevine A. Shalaby, Raheel Sayed, Qiao Zhang, Shane Scoggin, Susan Eliazer, Adrian Rothenfluh, and Michael Buszczak. Systematic discovery of genetic modulation by Jumonj histone demethylases in Drosophila. Scientific Reports, 7(1):5240, dec 2017. ISSN 20452322. doi: 10.1038/s41598-017-05004-w.

73. G. Shohat-Ophir, K. R. Kaun, R. Azanchi, and U. Heberlein. Sexual deprivation increases ethanol intake in Drosophila. Science, 335(6074):1351-1355, mar 2012. ISSN 10959203. doi: 10.1126/science. 1215932 .

74. Alison L. Camiletti, David N. Awde, and Graham J. Thompson. How flies respond to honey bee pheromone: the role of the foraging gene on reproductive response to queen mandibular pheromone. Naturwissenschaften, 101(1):25-31, jan 2014. ISSN 0028-1042. doi: 10.1007/s00114-013-1125-3.

75. Clement F. Kent, Tim Daskalchuk, Lisa Cook, Marla B. Sokolowski, and Ralph J. Greenspan. The Drosophila foraging Gene Mediates Adult Plasticity and Gene-Environment Interactions in Behaviour, Metabolites, and Gene Expression in Response to Food Deprivation. PLOS Genetics, 5(8):e1000609, aug 2009. ISSN 1553-7404. doi: 10.1371/journal.pgen.1000609.

76. Kristin Branson, Alice A. Robie, John Bender, Pietro Perona, and Michael H. Dickinson. High-throughput ethomics in large groups of Drosophila. Nature Methods, 6(6):451-457, may 2009. ISSN 15487091. doi: 10.1038/nmeth.1328.

77. Mayank Kabra, Alice A Robie, Marta Rivera-Alba, Steven Branson, and Kristin Branson. JAABA: interactive machine learning for automatic annotation of animal behavior. Nature Methods, 10(1):64-67, jan 2013. ISSN 1548-7091. doi: 10.1038/nmeth.2281.

78. Karla R Kaun, Reza Azanchi, Zaw Maung, Jay Hirsh, and Ulrike Heberlein. A Drosophila model for alcohol reward. Nature Neuroscience, 14(5):612-619, may 2011. ISSN 10976256. doi: 10.1038/nn.2805.

79. Kavin M. Nunez, Reza Azanchi, and Karla R. Kaun. Cue-Induced Ethanol Seeking in Drosophila melanogaster Is Dose-Dependent. Frontiers in Physiology, 9(APR):438, apr 2018. ISSN 1664-042X. doi: 10.3389/fphys.2018.00438.

80. Karen H. Berger, Eric C. Kong, Josh Dubnau, Tim Tully, Monica S. Moore, and Ulrike Heberlein. Ethanol Sensitivity and Tolerance in Long-Term Memory Mutants of Drosophila melanogaster. Alcoholism: Clinical and Experimental Research, 32(5):895-908, may 2008. ISSN 0145-6008. doi: 10.1111/j.1530-0277.2008.00659.x.

81. Douglas J. Levey. The Evolutionary Ecology of Ethanol Production and Alcoholism. Integrative and Comparative Biology, 44(4):284-289, aug 2004. ISSN 1540-7063. doi: 10.1093/icb/44.4.284.

82. K. R. Kaun, C. A. L. Riedl, M Chakaborty-Chatterjee, A. T. Belay, S. J. Douglas, A. G.
Gibbs, and M. B. Sokolowski. Natural variation in food acquisition mediated via a Drosophila cGMP-dependent protein kinase. Journal of Experimental Biology, 210(20): 3547-3558, oct 2007. ISSN 0022-0949. doi: 10.1242/jeb.006924.

83. Robert Feil, Jana Hartmann, Chongde Luo, Wiebke Wolfsgruber, Karl Schilling, Susanne Feil, Jaroslaw J. Barski, Michael Meyer, Arthur Konnerth, Chris I. De Zeeuw, and Franz Hofmann. Impairment of LTD and cerebellar learning by Purkinje cell-specific ablation of cGMP-dependent protein kinase I. Journal of Cell Biology, 163(2):295-302, oct 2003. ISSN 1540-8140. doi: 10.1083/jcb.200306148.

84. Cindy Paul, F. Schoberl, Pascal Weinmeister, Vincenzo Micale, Carsten T. Wotjak, Franz Hofmann, and Thomas Kleppisch. Signaling through cGMP-Dependent Protein Kinase I in the Amygdala Is Critical for Auditory-Cued Fear Memory and Long-Term Potentiation. Journal of Neuroscience, 28(52):14202-14212, dec 2008. ISSN 0270-6474. doi: 10.1523/ JNEUROSCI.2216-08.2008.

85. Marc A. Schuckit. A Critical Review of Methods and Results in the Search for Genetic Contributors to Alcohol Sensitivity. Alcoholism: Clinical and Experimental Research, 42 (5):822-835, may 2018. ISSN 01456008. doi: 10.1111/acer.13628.

86. Andrea C. King, Patrick J. McNamara, Deborah S. Hasin, and Dingcai Cao. Alcohol Challenge Responses Predict Future Alcohol Use Disorder Symptoms: A 6-Year Prospective Study. Biological Psychiatry, 75(10):798-806, may 2014. ISSN 00063223. doi: 10.1016/j.biopsych.2013.08.001.

87. Thomas M. Piasecki, Kyle J. Alley, Wendy S. Slutske, Phillip K. Wood, Kenneth J. Sher, Saul Shiffman, and Andrew C. Heath. Low Sensitivity to Alcohol: Relations With Hangover Occurrence and Susceptibility in an Ecological Momentary Assessment Investigation. Journal of Studies on Alcohol and Drugs, 73(6):925-932, nov 2012. ISSN 1937-1888. doi: 10.15288/jsad.2012.73.925.

88. J. Crabbe, J. Belknap, and K. Buck. Genetic animal models of alcohol and drug abuse. Science, 264(5166):1715-1723, jun 1994. ISSN 0036-8075. doi: 10.1126/science.8209252.

89. Marc A. Schuckit. Low level of response to alcohol as a predictor of future alcoholism American Journal of Psychiatry, 151(2):184-189, feb 1994. ISSN 0002-953X. doi: 10. 1176/ajp.151.2.184.

90. Marc A Schuckit. Alcohol sensitivity and dependence. Toward a molecular basis of alcohol use and abuse, pages 341-348, 1994.

91. Tatiana V. Morozova, Julien F. Ayroles, Katherine W. Jordan, Laura H. Duncan, Mary Anna Carbone, Richard F. Lyman, Eric A. Stone, Diddahally R. Govindaraju, R. Curtis Ellison, Trudy F. C. Mackay, and Robert R. H. Anholt. Alcohol Sensitivity in Drosophila: Translational Potential of Systems Genetics. Genetics, 183(2):733-745, oct 2009. ISSN 00166731. doi: 10.1534/genetics.109.107490.

92. Tatiana V Morozova, Robert RH Anholt, and Trudy FC Mackay. Phenotypic and transcrip tional response to selection for alcohol sensitivity in Drosophila melanogaster. Genome Biology, 8(10):R231, 2007. ISSN 1465-6906. doi: 10.1186/gb-2007-8-10-r231.

93. Henrike Scholz, Jennifer Ramond, Carol M. Singh, and Ulrike Heberlein. Functional Ethanol Tolerance in Drosophila. Neuron, 28(1):261-271, oct 2000. ISSN 08966273. doi: 10.1016/S0896-6273(00)00101-X.

94. C M Singh and U Heberlein. Genetic control of acute ethanol-induced behaviors in Drosophila. Alcoholism, clinical and experimental research, 24(8):1127-36, aug 2000. ISSN 0145-6008.

95. Tatiana V. Morozova, Wen Huang, Victoria A. Pray, Thomas Whitham, Robert R. H. Anholt, and Trudy F. C. Mackay. Polymorphisms in early neurodevelopmental genes affect natura variation in alcohol sensitivity in adult drosophila. BMC Genomics, 16(1):865, dec 2015 ISSN 1471-2164. doi: 10.1186/s12864-015-2064-5.

96. Anne-Sophie Philippe, Raphael Jeanson, Cristian Pasquaretta, Francois Rebaudo, Cedric Sueur, and Frederic Mery. Genetic variation in aggregation behaviour and interacting phenotypes in drosophila. Proceedings of the Royal Society B: Biological Sciences, 283 (1827):20152967, 2016.

97. Silu Wang and Marla B Sokolowski. Aggressive behaviours, food deprivation and the foraging gene. Royal Society open science, 4(4):170042, 2017.

98. Nancy R Kohn, Christopher J Reaume, Celine Moreno, James G Burns, Marla B Sokolowski, and Frederic Mery. Social environment influences performance in a cognitive task in natural variants of the foraging gene. PloS one, 8(12):e81272, 2013.

99. Murray W McConnell and Mark J Fitzpatrick. 'foraging'for a place to lay eggs: A genetic link between foraging behaviour and oviposition preferences. Plos one, 12(6):e0179362, 2017

100. Y Ben-Shahar, A Robichon, MB Sokolowski, and GE Robinson. Influence of gene action across different time scales on behavior. Science, 296(5568):741-744, 2002.

101. Y Ben-Shahar, H-T Leung, WL Pak, MB Sokolowski, and GE Robinson. cgmp-dependent changes in phototaxis: a possible role for the foraging gene in honey bee division of labor. Journal of Experimental Biology, 206(14):2507-2515, 2003.

102. Ebi A George, Ann-Kathrin Bröger, Markus Thamm, Axel Brockmann, and Ricarda Scheiner. Inter-individual variation in honey bee dance intensity correlates with expression of the foraging gene. Genes, Brain and Behavior, 19(1):e12592, 2020.

103. Tom Wenseleers, Johan Billen, Lut Arckens, Julie Tobback, Roger Huybrechts, Kevin Heylen, and Bruno Gobin. Cloning and expression of pkg, a candidate foraging regulating gene in vespula vulgaris. Animal Biology, 58(4):341-351, 2008.

104. Krista K Ingram, Peter Oefner, and Deborah M Gordon. Task-specific expression of the foraging gene in harvester ants. Molecular Ecology, 14(3):813-818, 2005.

105. Christophe Lucas and Marla B Sokolowski. Molecular basis for changes in behavioral state in ant social behaviors. Proceedings of the National Academy of Sciences, 106(15): 6351-6356, 2009

106. N. Alwash, A. Allen, Marla B. Sokolowski, and J. Levine. The drosophila melanogaster foraging gene affects social networks. Journal of Neurogenetics, 2021. 